\title{
A proposed capillary number dependent model for prediction of relative permeability in gas condensate reservoirs: a robust non-linear regression analysis
}

\author{
Mehdi Mahdaviara ${ }^{1,{ }^{*}}$ and Abbas Helalizadeh ${ }^{2}$ \\ ${ }^{1}$ Department of Petroleum Engineering, Omidieh Branch, Islamic Azad University, 6373193719 Omidieh, Iran \\ ${ }^{2}$ Department of Petroleum Engineering, Petroleum University of Technology (PUT), 6199171183 Ahwaz, Iran
}

Received: 20 March 2019 / Accepted: 5 March 2020

\begin{abstract}
Well deliverability reduction as a result of liquid (condensate) build up in near well regions is an important deal in the development of gas condensate reservoirs. The relative permeability is an imperative factor for characterization of the aforementioned problem. The dependence of relative permeability on the coupled effects of Interfacial Tension (IFT) and flow velocity (capillary number) together with phase saturation is well established in the literature. In gas condensate reservoirs, however, the influence of IFT and velocity on this parameter becomes more evident. The current paper aims to establish a new model for predicting the relative permeability of gas condensate reservoirs by employing the direct interpolation technique. To this end, the regression analysis was carried out using seven sets of literature published experimental data. The validity analysis was executed by utilizing statistical parameters integrated with graphical descriptions. Furthermore, a comparison was carried out between the proposed model and some literature published empirical models. The results of the examination demonstrated that the new model outperformed other correlations from the standpoints of accuracy and reliability.
\end{abstract}

\section{Nomenclature}

\section{Latin letters}

$c_{\mathrm{d}} \quad$ Drag coefficient

$D_{\mathrm{m}} \quad$ Mean grain size of the core

$f \quad$ Weighting factor for linking $k_{\mathrm{r}}$ to capillary

number

$\widetilde{f} \quad$ Weighting factor for linking $s_{\text {ir }}$ to capillary

$k \quad$ Absolute permeability, md

$k_{\mathrm{r}} \quad$ Relative permeability

$k_{\mathrm{r}}^{*} \quad$ End point relative permeability

$k_{\mathrm{rg}} / k_{\mathrm{rc}}$

$n, m, a, b$,

and $c \quad$ Regression parameters (constants)

$N_{\text {c }} \quad$ Capillary number; the ratio of viscous to

capillary forces

$N_{\text {cb }} \quad$ Base capillary number

Re Reynolds number; the ratio of inertia to viscous forces

* Corresponding author: mmahdavia@yahoo.com

$\begin{array}{ll}\operatorname{Re}_{\mathrm{c}} & \text { Critical Reynolds number } \\ S_{\mathrm{r}} & \text { Residual saturation } \\ S_{\mathrm{r}}^{*} & \text { Normalized residual saturation } \\ S_{\mathrm{wc}} & \text { Connate water saturation } \\ v & \text { Velocity } \mathrm{ft} / \mathrm{d}\end{array}$

\section{Greek letters}

$\beta$

$\varepsilon$

$\mu$

$\rho$

$\sigma$

$\sigma_{\mathrm{b}}$

$\phi$

\section{Subscripts}

$\begin{array}{ll}c & \text { Condensate phase } \\ g & \text { Gas phase }\end{array}$


$i \quad$ Phase indicator (gas or condensate)

$\mathrm{M}$

Miscible condition

\section{Abbreviations}

$\begin{array}{ll}\text { CDC } & \text { Capillary Desaturation Curve } \\ \text { IFT } & \text { Interfacial Tension }\end{array}$

\section{Introduction}

The unique properties of the fluid in gas condensate reservoirs distinguishes its flow behavior from other oil and gas reservoirs. Condensate banking in near-well regions is a momentous phenomenon that affects the fluid flow in porous media. This phenomenon occurs as a result of pressure dropping below reservoir fluids dew point pressure. The condensate banking plays an important role in welldeliverability because it brings about the accumulation of heavier components of the gas in pore space. In fact, a gas condensate reservoir can chock on its most valuable components, namely condensate (Fan et al., 2005). Therefore, a two-phase gas/condensate system (or three phases when water is presented) emerges, in which diagnosing the special manner of fluid flow/distribution in porous media (especially in the near well condition) is essential for production management.

The relative permeability $\left(k_{\mathrm{r}}\right)$ indicates the competition between the phases for flowing in porous media on a macroscopic scale. This parameter mainly alters as a function of fluid saturation. However, the dependence of relative permeability and residual saturation $\left(S_{\mathrm{r}}\right)$ on the ratio of viscous to capillary forces (denoted by the capillary number, $N_{\mathrm{c}}$ ) in a microscopic/pore scale is well established in the literature (Ahmadi et al., 2019; Avraam and Payatakes, 1995; Delshad et al., 1986; Fulcher et al., 1985; Johannesen and Graue, 2007; Tsakiroglou, 2019; Tsakiroglou et al., 2007).

Avraam and Payatakes (1995) have represented a pioneering work evaluating the relative permeability and flow regime behaviors during a steady-state oil-water flow in a model pore space. They reported a robust relationship between the oil and water relative permeabilities and capillary number, the viscosity ratio, and the flow rate ratio. Both oil and water relative permeabilities increased by an increase in the capillary number. The foregoing relationship was related to the distribution of the oil ganglia/droplets, based on which the flow regime was classified into LargeGanglion Dynamics (LGD), Small-Ganglion Dynamics (SGD), Drop-Traffic Flow (DTF), and Connected Pathway Flow (CPF). The formation of connected oil pathways was corresponded to the largest capillary numbers and relative permeabilities. Fulcher et al. (1985) have implemented a steady-state relative permeability measurement to investigate the effect of capillary number on the relative permeability curves. They also observed a close relationship between these parameters, especially in the case of low IFTs. Tsakiroglou et al. (2007) have utilized the history matching of transient flow experiments to assess the relative permeabilities of oil and water phases. A glass-etched water wet pore network and two fluid systems with intermediate and strong wettabilities were employed for this purpose. Their analysis also revealed the vigorous correlation between the relative permeability and the capillary number. The two-phase flow structure (steady-state flow regime and transient growth pattern) and the wettability type (intermediate and strong) were found as important factors influencing the foregoing $k_{\mathrm{r}}-N_{\mathrm{c}}$ relationship. The transient $k_{\mathrm{r}}$ of both phases was an increasing function of $N_{\mathrm{c}}$ in the case of strong wettability. The transient flow was associated with higher oil relative permeability in comparison to the steady-state regime, whereas the steady-state water relative permeability exceeded the transient one over the low $N_{\mathrm{c}}$. Tsakiroglou (2019) has also carried out a steady-state two-phase flow experiment to assess the relative permeability of the nitrogen and brine in a homogeneous sand system. He reported a robust direct relationship between the gas and water relative permeabilities and the gas and water capillary numbers, respectively. The foregoing relationship was also observed in the work of Ahmadi et al. (2019) in an attempt to investigate the effect of capillary number and reservoir heterogeneity on the location of injection/production wells using Computational Fluid Dynamics (CFD) approach. It is noteworthy that the aforementioned $k_{\mathrm{r}}-N_{\mathrm{c}}$ relationship defines a Capillary Desaturation Curve (CDC). This parameter has been widely investigated in the context of IOR processes including water and chemical flooding (Delshad et al., 2009; Guo et al., 2015).

Furthermore, the ratio of the inertia to viscous forces (represented by Reynolds number) was found to be a significant factor influencing the $k_{\mathrm{r}}$ and $S_{\mathrm{r}}$ parameters (Henderson et al., 2000b). The Reynolds number plays a vital role in characterizing the governing flow regimes including laminar and turbulent. There are extraordinary discrepancies between fluid flow in the porous media and a conduit. The transition between the laminar and turbulent flows is not detected obviously in the porous media (van Lopik et al., 2017). Furthermore, the flow regime categorization is different in the stochastic nature of the hydrocarbon-bearing reservoirs. Dybbs and Edwards (1984) believe that the Reynolds number ranges of $1-10,10-150$, 150-250, 250-300, and greater than 300 correspond to the inertial core establishment, non-linear steady laminar flow, unsteady laminar flow, transition between unsteady and highly unsteady laminar, and chaotic (turbulent) flow, respectively (Al-Shaidi, 1997). Hence, the flow regime, as well as governing forces, serve as momentous factors affecting the relative permeability of the reservoir.

Typically, the distribution of the phases in pore spaces is dominated by capillary forces (Blom and Hagoort, 1998). The magnitude of the capillary forces is determined by Interfacial Tension (IFT), wettability, and pore geometry (Delshad et al., 1986). It is well recognized that a reduction in interfacial tension (the capillary number increment) will entail an increase in relative permeability as well as fluid residual saturations reduction $\left(S_{\mathrm{r}}\right)$ (Amaefule and Handy, 1982; Chukwudeme et al., 2014). In gas condensate reservoirs, however, the viscous forces may be of the same order of magnitude as the capillary 
forces (Blom and Hagoort, 1998). The immensity of the viscous forces is set by the fluid viscosity, flow velocity, and flow path length (Fulcher et al., 1985). It has been widely accepted that the foregoing connection between the IFT and $k_{\mathrm{r}} / S_{\mathrm{r}}$ becomes momentous when the IFT is lower than its critical (base) value (IFT 1988; Kalla et al., 2014; Longeron, 1980). Additionally, many researchers have been confirmed experimentally that relative permeability of the gas condensate fluids (in particular for the gas phase) increase with the velocity at low/moderate flow velocities (Henderson et al., 1997, 2000a; Jamiolahmady et al., 2008; Mott et al., 1999). Conversely, relative permeability reduction with an increase in velocity at high velocities is also well established. This phenomenon takes place as a result of non-Darcy flow in the vicinity of the wellbore (in particular for the gas phase).

The positive effect of IFT together with low/moderate velocities on relative permeability has been termed "coupling effect" (Avraam and Payatakes, 1995; Henderson et al., 2000a; Jamiolahmady et al., 2008, 2009); and the negative effect of high velocities on this parameter is known as "inertia effect". Accordingly, the interaction of coupling and inertia effects determines the shape and the value of relative permeability curves (Henderson et al., 2000b).

Taking into account the coupling and inertia effects, as well as saturation, relies at the heart of the relative permeability measurement/calculation in gas condensate reservoirs. Since the relative permeability experimentally measurement process is expensive and time-consuming, correlations describing relative permeability are extremely useful in the absence of laboratory-measured data. Accordingly, there are several literature-published correlations for estimation of relative permeability in conventional reservoirs containing immiscible fluids (Brooks and Corey, 1964; Lomeland et al., 2005; Stone, 1973). Additionally, different researchers have been attempted to link the relative permeability of immiscible fluids to the capillary number and saturation in accordance to the steady-state two-phase flow experiments (Lenormand et al., 1988; Payatakes, 1982; Tsakiroglou et al., 2007, 2015).

In the case of gas condensate and near-critical fluids, various empirical models have been developed with respect to the fact that the coupled effects of IFT and velocity momentously dominate the relative permeability curves of the foregoing fluids (Coats, 1980; Jamiolahmady et al., 2009; Pope et al., 2000; Whitson and Fevang, 1997). The majority of the aforesaid correlations employ the $N_{\mathrm{c}}$ for taking into account the coupling effect (Al-Shaidi, 1997; Whitson and Fevang, 1997). However, since the positive effect of velocity on relative permeability was not perceived by early authors, they proposed models directly according to the IFT (Betté et al., 1991; Coats, 1980; Nghiem et al., 1981). Additionally, Jamiolahmady et al. (2006) employed both IFT and $N_{\mathrm{c}}$ parameters simultaneously, because they believed that presence of IFT in the denominator of $N_{\mathrm{c}}$ equation does not enough to express the dependency on IFT. Furthermore, Pope et al. (2000) utilized trapping number (a generalization of the capillary and bond numbers) as an alternative to the $N_{\mathrm{c}}$ in order to account for the gravitational forces.
Blom and Hagoort (1998) divided the foregoing correlations into two major categories according to the manner of including the capillary number:

1. Utilizing Corey function, in which its coefficients were linked to $N_{\mathrm{c}}$ (Eq. (1)) (App and Burger, 2009; Blom and Hagoort, 1998; Fulcher et al., 1985):

$$
k_{\mathrm{ri}}\left(N_{\mathrm{c}}, s_{i}\right)=k_{\mathrm{ri}}^{*}\left(N_{\mathrm{c}}\right)\left(\frac{s_{i}-s_{\mathrm{ri}}\left(N_{\mathrm{c}}\right)}{1-s_{\mathrm{ri}}\left(N_{\mathrm{c}}\right)-s_{\mathrm{wc}}}\right)^{\varepsilon_{i}\left(N_{\mathrm{c}}\right)}
$$

where $i$ refers to phase type (gas or condensate), $k_{\mathrm{ri}}$ $\left(N_{\mathrm{c}}, s_{i}\right)$ stands for saturation/capillary number dependent relative permeability; and $k_{\mathrm{ri}}^{*}\left(N_{\mathrm{c}}\right), S_{\mathrm{ri}}\left(N_{\mathrm{c}}\right)$ and $\varepsilon_{i}\left(N_{\mathrm{c}}\right)$ are capillary number (or IFT) dependent Corey coefficients. The $k_{\mathrm{ri}}^{*}\left(N_{\mathrm{c}}\right)$ denotes the endpoint relative permeability, $S_{\mathrm{ri}}\left(N_{\mathrm{c}}\right)$ stands for residual saturation and $\varepsilon_{i}\left(N_{\mathrm{c}}\right)$ is the Corey component, which fixes the curvature of the relative permeability function.

2. Interpolation between miscible and immiscible relative permeability curves (Eq. (2)) (Amaefule and Handy, 1982; Betté et al., 1991; Henderson et al., 2000a; Jamiolahmady et al., 2009; Whitson and Fevang, 1997):

$$
K_{\mathrm{ri}}\left(N_{\mathrm{c}}, s_{i}\right)=f_{i}\left(N_{\mathrm{c}}\right) K_{\mathrm{riI}}+\left[1-f_{i}\left(N_{\mathrm{c}}\right)\right] K_{\mathrm{riM}},
$$

where $k_{\text {riI }}$ and $k_{\text {rim }}$ are immiscible (or rock) and miscible (or straight line) relative permeabilities, respectively. All the intermediate relative permeability points are situated between these two limits. The $f_{i}\left(N_{\mathrm{c}}\right)$, an $N_{\mathrm{c}}$ dependent function, determines the proximity of the relative permeability curve to the aforesaid limits. The value of this weighting factor changes between 0 for fully miscible (high $N_{\mathrm{c}}$ ), and 1 (low $N_{\mathrm{c}}$ ) for completely immiscible mixtures.

To the best of authors' knowledge, Coats (1980) has employed the interpolation technique for the first time to link the $k_{\mathrm{r}}$ to the IFT. This simple intuitive approach (without any explicit physical meaning) has been grabbed the attention of the majority of researchers (Amaefule and Handy, 1982; Betté et al., 1991; Henderson et al., 2000a; Jamiolahmady et al., 2009; Whitson and Fevang, 1997). Different authors have proposed various weighting factors for linking the $k_{\mathrm{r}} / S_{\mathrm{r}}$ to the $N_{\mathrm{c}}$. Furthermore, Whitson and Fevang (1997) interpolated the $k_{\mathrm{r}}$ points as a function of non-wet to wet relative permeability ratio $\left(k_{\mathrm{rg}} / k_{\mathrm{rc}}\right)$ as an alternative to saturation. Accordingly, the $S_{\mathrm{r}}-N_{\mathrm{c}}$ relationship was ignored. However, this technique was only applicable to near-wellbore regions, where both gas and condensate phases are flowing.

For considering the negative effect of inertia, on the other hand, the Forchheimer equation (Eq. (3)) has been employed as follows (App and Burger, 2009; Jamiolahmady et al., 2009; Whitson et al., 1999):

$$
\frac{\mathrm{d} P}{\mathrm{~d} L}=\frac{\mu v}{k}+\beta \rho v^{2},
$$


where $\beta$ stands for Forchheimer (or non-Darcy) coefficient with $L^{-1}$ dimension, $k$ is absolute permeability, and $\rho, v$, and $\mu$ denote density, velocity, and viscosity.

Although the aforementioned correlations are worthwhile in the absence of experimental data, they are associated with shortcomings in various aspects. The majority of these models suffer from a large number of tuning parameters (constants), in which the setting value of each parameter is divergent for various cases. Accordingly, designating the expedient values for aforesaid regression parameters is a tough duty. The problem becomes even more pronounced when the accuracy and reliability of each model are not unique for various rock and fluid systems. Each model has been correlated by implementing a special experiment on a limited number of rock and fluid systems and experimental conditions. Accordingly, there is uncertainty for choosing the most appropriate model for estimation of relative permeability in a particular gas condensate reservoir.

In order to alleviate these limitations in the current study, the authors attempted to develop a new reliable model for the prediction of $k_{\mathrm{r}}$ in gas condensate reservoirs as a function of $N_{\mathrm{c}}$ as well as saturation. The authors aimed advantages of simplicity and the least number of tuning parameters (constants)/variables integrated with averagely high reliability for various rock and fluid systems. To this end, regression analysis was carried out by employing seven sets of literature experimentally data (Asar and Handy, 1988; Calisgan and Akin, 2008; Chen et al., 1995; Haniff and Ali, 1990; Henderson et al., 1997, 1988; Longeron, 1980). The Capillary and Reynolds numbers were assessed to recognize the governing flow regime/forces over the utilized datasets. The performance of the developed correlations was investigated using statistical parameters of Root Mean Square Error (RMSE) and determination coefficient $\left(R^{2}\right)$. The validity of the aforesaid empirical functions was evaluated by implementing a comparison with other literature proposed models (Al-Shaidi, 1997; Coats, 1980; Jamiolahmady et al., 2009; Nghiem et al., 1981; Whitson and Fevang, 1997). To provide more investigation regarding the accuracy of the developed model, curve fitting analysis was carried out by utilizing a set of previously published data (Blom et al., 1997) which had been excluded from the regression procedure.

\section{Model description}

\subsection{Applying the coupling effect}

Two different structures of the direct interpolation were utilized for linking the $N_{\mathrm{c}}$ (coupling effect) to the relative permeability:

1. The relative permeability curves as functions of phase saturation:

$$
\begin{aligned}
K_{\mathrm{ri}}\left(N_{\mathrm{ci}}, s_{i}\right)= & f_{i}\left(N_{\text {ci }}\right) K_{\text {riI }}\left(s_{i}, s_{\mathrm{ir}}\right) \\
& +\left[1-f_{i}\left(N_{\text {ci }}\right)\right] K_{\text {riM }}\left(s_{i}, s_{\mathrm{ir}}\left(N_{\mathrm{ci}}\right)\right),
\end{aligned}
$$

where $K_{\mathrm{riI}}\left(s_{i}, s_{\mathrm{ir}}\right)$ denotes saturation dependent immiscible relative permeability, and $K_{\mathrm{riM}}\left(s_{i}, s_{\mathrm{ir}}\left(N_{\mathrm{ci}}\right)\right)$ stands for miscible relative permeability, which alters as a function of capillary number dependence residual saturation as well as phase saturation.

2. The relative permeability curves as functions of nonwet to wet relative permeability ratio $\left(k_{\mathrm{rg}} / k_{\mathrm{rc}}\right)$ instead of saturation:

$$
K_{\mathrm{ri}}\left(N_{\mathrm{ci}}, \frac{k_{\mathrm{rg}}}{k_{\mathrm{rc}}}\right)=f_{i}\left(N_{\mathrm{ci}}\right) K_{\mathrm{riI}}\left(\frac{k_{\mathrm{rg}}}{k_{\mathrm{rc}}}\right)+\left[1-f_{i}\left(N_{\mathrm{ci}}\right)\right] K_{\mathrm{riM}}\left(\frac{k_{\mathrm{rg}}}{k_{\mathrm{rc}}}\right),
$$

where $k_{\mathrm{riI}}\left(k_{\mathrm{rg}} / k_{\mathrm{rc}}\right)$ and $k_{\mathrm{riM}}\left(k_{\mathrm{rg}} / k_{\mathrm{rc}}\right)$ are immiscible and miscible relative permeabilities, respectively. The aforementioned parameters are functions of non-wet to wet relative permeability ratio $\left(k_{\mathrm{rg}} / k_{\mathrm{rc}}\right)$ instead of saturation.

\subsubsection{The weighting factor}

A vast variety of data points from seven sets of literature published datasets (Asar and Handy, 1988; Calisgan and Akin, 2008; Chen et al., 1995; Haniff and Ali, 1990; Henderson et al., 1997, 1988; Longeron, 1980) were employed to develop a precise and reliable weighting function. To this end, regression analysis was carried out using Gauss-Newton and Levenberg-Marquardt algorithms. This examination led to the following logistic weighting factor:

$$
f_{i}\left(N_{\mathrm{ci}}\right)=\frac{A_{i}}{1+Q_{i} \exp \left(B_{i} \times \frac{N_{\mathrm{ci}}}{N_{\mathrm{cib}}}\right)},
$$

where $i$ stands for phase type (namely gas or condensate), $N_{\text {ci }}$ denotes the capillary number, and $N_{\text {cib }}$ represents the base capillary number, below which the relative permeability of the gas and condensate becomes independent from the capillary number (namely, the value of the capillary number at immiscible condition; i.e., at highest IFT and lowest velocity). The entities $A_{i}, Q_{i}$, and $B_{i}$ are the tuning parameters (constants) of the equation. Default values for the entities $A_{i}$ and $Q_{i}$ are 2 and 1, respectively. Given these values, $B_{i}$ changes between 0 and 0.5 for both gas and condensate phases. The value of the $B_{i}$ parameter is relatively unique for gas and condensate phases $\left(B_{\mathrm{g}} \approx B_{\mathrm{c}}\right)$. Furthermore, a correlation was developed for linking the tuning parameter of $B_{i}$ to the multiplication of porosity and permeability as follows:

$$
B_{i}=a_{i} \cdot \frac{m_{i} s_{i}^{n_{i}}}{(\emptyset \cdot \mathrm{k})^{c_{i}}},
$$

where, the entities $\varphi$ and $k$ are porosity and absolute permeability (md), respectively. The default values of $m_{i}$ and $c_{i}$ for both phases are 3 and 1 , respectively. The value of $n_{i}$ is 0.63 and 1.77 for gas and condensate phases, respectively.

For small $N_{c}$, capillary forces dominate and traditional (immiscible) relative permeability behavior is found. Consequently, for large $N_{\mathrm{c}}$, viscous forces dominate and relative permeabilities tend to approach straight lines or miscible like behavior (Whitson et al., 1999). Hence, the value of the proposed weighting factor of equation (6) alters 
between 0 and 1 for thoroughly miscible (high $N_{\mathrm{c}}$ ) and completely immiscible (small $N_{\mathrm{c}}$ ) conditions, respectively.

\subsubsection{The immiscible relative permeability}

Conventional experimental measurements or traditional correlations such as Brooks and Corey (1964) and Stone (1973) can be employed to achieve the immiscible relative permeability curves.

\subsubsection{The miscible relative permeability}

The modified relative permeability correlation of equation (1) is proposed for the miscible state:

$$
k_{\mathrm{riM}}=\frac{s_{i}-s_{\mathrm{ir}}\left(N_{\mathrm{ci}}\right)}{1-s_{\mathrm{wc}}-s_{\mathrm{ir}}\left(N_{\mathrm{ci}}\right)}=\frac{s_{i}^{*}-s_{\mathrm{ir}}^{*}\left(N_{\mathrm{ci}}\right)}{1-s_{\mathrm{ir}}^{*}\left(N_{\mathrm{ci}}\right)},
$$

where $s_{\mathrm{wc}}$ stands for connate water saturation, $s_{\mathrm{ir}}\left(N_{\mathrm{c}}\right)$ is capillary number dependent residual saturation and $s_{\mathrm{ir}}^{*}$ $\left(N_{\mathrm{c}}\right)$ denotes normalized capillary number dependent residual saturation.

This is noteworthy that the following expression can be utilized for obtaining the miscible relative permeability curves directly as a function of $k_{\mathrm{rg}} / k_{\mathrm{rc}}$ :

$$
k_{\mathrm{rgM}}=\frac{1-s_{\mathrm{wc}}}{1+\left(k_{\mathrm{rg}} / k_{\mathrm{rc}}\right)^{ \pm 1}},
$$

where $(-1)$ and $(+1)$ indexes must be used for calculation of the gas and condensate miscible relative permeabilities, respectively.

The residual saturation was related to the capillary number in the same manner of other literature published models:

$$
s_{\mathrm{ir}}\left(N_{\mathrm{c}}\right)=\widetilde{f}_{i}\left(N_{\mathrm{ci}}\right) s_{\mathrm{irI}},
$$

where $s_{\text {irr }}$ is the residual saturation at immiscible condition, and $\tilde{f}_{i}\left(N_{\mathrm{ci}}\right)$ denotes the weighting factor utilized for linking $s_{\text {irI }}$ to the $N_{\mathrm{c}}$. Regression analysis was executed once again in order to obtain a reliable expression for the aforesaid weighting function. The results of the analysis demonstrated that equation (6) is also reliable for connecting the capillary number to the residual saturation. Equation (6) makes use of the fact that residual saturation tends toward zero by an increase in the capillary number.

At the end, it should be worth pointing out that the effect of inertia can be considered by employing the Darcy equation integrated with Forchheimer expression as follows (Al-Shaidi, 1997):

$$
k_{\mathrm{ri}}\left(N_{\mathrm{ci}}, s_{i}, \beta_{i}\right)=\frac{1}{\frac{1}{k_{\mathrm{ri}}\left(N_{\mathrm{ci},}, s_{i}\right)}+1.83 \times 10^{-16} \beta_{i} \cdot k \cdot \operatorname{Re}},
$$

where $k_{\mathrm{ri}}\left(N_{\mathrm{ci}}, s_{i}, \beta_{i}\right)$ is coupling, saturation, and inertia dependent relative permeability, $k$ denotes the absolute permeability in md, $\beta_{i}$ stands for Forchheimer coefficient in $\mathrm{ft}^{-1}$, and Re is the Reynolds number which defines as the ratio of inertial to viscous forces as follows:

$$
\operatorname{Re}=\frac{\rho_{i} v_{i}}{\mu_{i}},
$$

where the entity $\rho_{i}$ is density in $\mathrm{lb}_{\mathrm{m}} / \mathrm{ft}^{3}, v_{i}$ denotes the velocity in $\mathrm{ft} / \mathrm{d}$, and $\mu_{i}$ is viscosity in cp.

Thereby, for a given saturation or $k_{\mathrm{rg}} / k_{\mathrm{rc}}$ point, the gas condensate relative permeability can be estimated according to the following steps:

1. Calculate the immiscible relative permeability using experimental measurements or traditional correlations such as Brooks and Corey (1964) and Stone (1973).

2. Link the residual saturation to the capillary number by utilizing equation (10) integrated with equation (6).

3 . Calculate the miscible relative permeability by employing equations (8) or (9).

4. Measure the value of the weighting factor using equation (6).

5. Estimate the capillary number dependent relative permeability of the given saturation and $/$ or $k_{\mathrm{rg}} / k_{\mathrm{rc}}$ point by manipulating equations (4) or (5).

6. Utilize equation (11) for applying the influence of inertia.

The flowchart of Figure 1 represents a visual description of the sequence of relative permeability prediction for gas condensate reservoirs.

\section{Results and discussions}

In the current study, a cumulative of seven datasets were collected from the literature (Asar and Handy, 1988; Calisgan and Akin, 2008; Chen et al., 1995; Haniff and Ali, 1990; Henderson et al., 1997, 1988; Longeron, 1980) for developing a model for prediction of relative permeability in gas condensate reservoirs. A description of the aforesaid datasets including rock and fluid properties as well as the experiment methods (namely, steady-state and unsteadystate) is represented in Table 1. As can be seen in the table, these datasets encompass various rock and fluid systems, experimental methods, and the widespread points of gas and condensate relative permeabilities as a function of saturation, IFT, and capillary number. Accordingly, the developed model becomes more applicable to predict the relative permeability of different gas condensate reservoirs.

The above-mentioned datasets reported the dependency of relative permeability to the velocity and IFT without addressing the flow nature/regime of the experiments. Accordingly, the pore-scale dimensionless numbers of Capillary and Reynolds were employed to assess the regimes/forces governing the fluid flow in each dataset. For this purpose, the pore-scale Capillary number was determined by utilizing the following literature correlation (Foster, 1973):

$$
N_{\mathrm{c}}=\frac{\mu_{i} v_{i}}{\sigma_{i} \emptyset} .
$$

Furthermore, the pore-scale Reynolds number was calculated as follows (Bear, 2013):

$$
\operatorname{Re}=\frac{\rho_{i} v_{i} D_{\mathrm{mi}}}{\mu_{i}},
$$




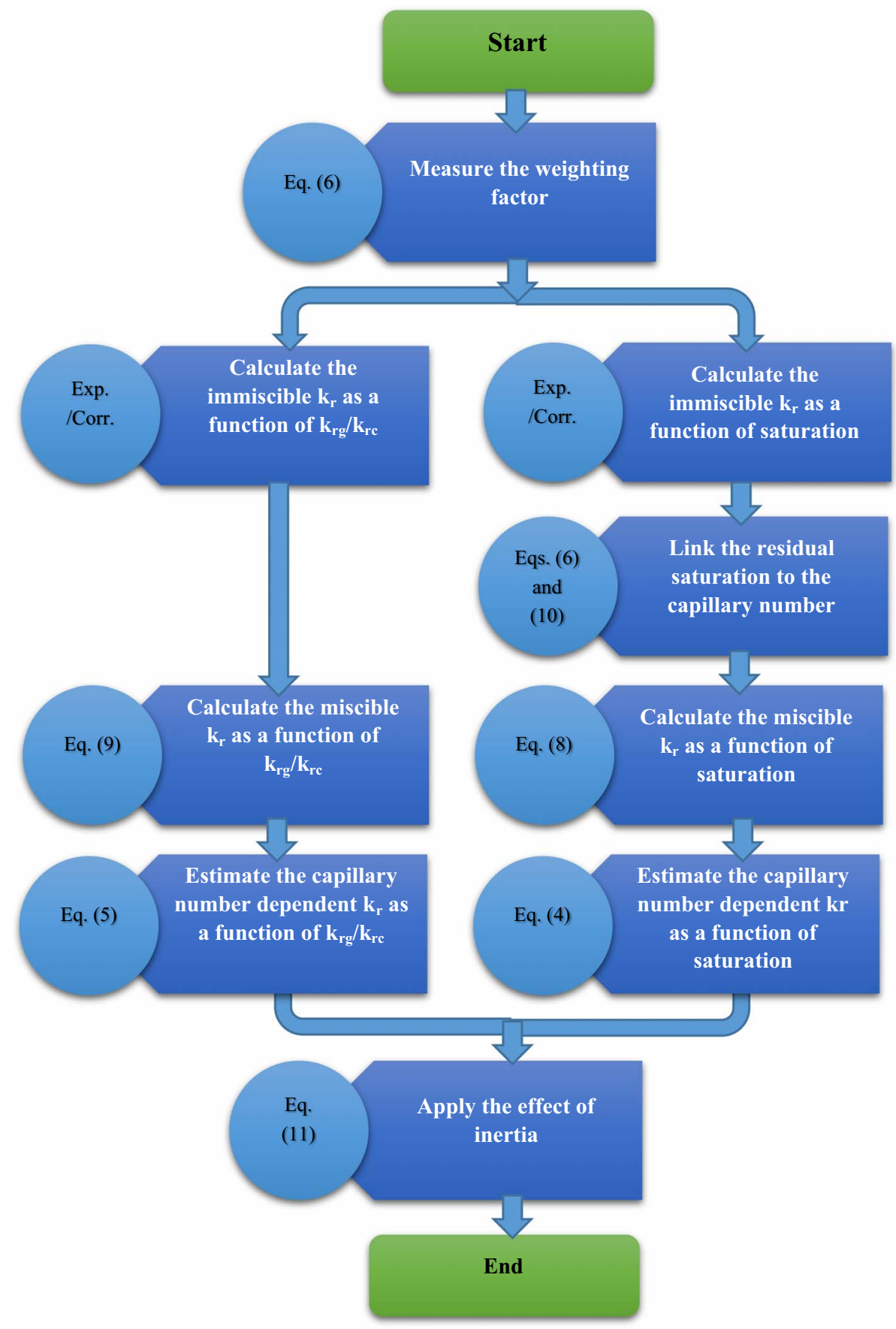

Fig. 1. Flowchart of the relative permeability estimation in gas condensate reservoirs.

where $D_{\mathrm{m}}$ stands for the mean grain size of the core. The following equation was utilized to calculate the foregoing parameter for each dataset (Urumović and Urumović, 2016):

$$
D_{\mathrm{m}}=\frac{(1-\emptyset)}{\emptyset} \sqrt{\frac{180 k}{\emptyset}}
$$

The critical Reynolds number, above which the inertia effect is dominant, was quantified as follows (Du Plessis and Woudberg, 2008):

$$
\operatorname{Re}_{\mathrm{c}}=\frac{50.8 \emptyset(1-\emptyset)^{1 / 3}}{c_{\mathrm{d}}\left(1-(1-\emptyset)^{1 / 3}\right)},
$$

where, $c_{\mathrm{d}}$ represents the drag coefficient, which corresponds to the value of 1.9 in the current study.

The values of the approximated Capillary and Reynolds numbers together with the critical Reynolds number are demonstrated in Table 2 for various experimental conditions. An expeditious examination of the Capillary number values indicates that the capillary forces are dominant 
Table 1. Summary of the experimental conditions of the seven literature datasets utilized in this study.

\begin{tabular}{|c|c|c|c|c|c|c|c|}
\hline Dataset & $\begin{array}{c}\text { Dataset } 1 \\
\text { (Longeron, } \\
1980) \\
\end{array}$ & $\begin{array}{c}\text { Dataset } 2 \\
\text { (Asar and } \\
\text { Handy, 1988) }\end{array}$ & $\begin{array}{c}\text { Dataset } 3 \\
\text { (Haniff and } \\
\text { Ali, 1990) }\end{array}$ & $\begin{array}{c}\text { Dataset } 4 \\
\text { (Chen et al., } \\
1995)\end{array}$ & $\begin{array}{l}\text { Dataset } 5 \\
\text { (Henderson } \\
\text { et al., 1997) }\end{array}$ & $\begin{array}{l}\text { Dataset } 6 \\
\text { (Henderson } \\
\text { et al., 1988) }\end{array}$ & $\begin{array}{c}\text { Dataset } 7 \\
\text { (Calisgan and } \\
\text { Akin 2008) }\end{array}$ \\
\hline $\begin{array}{l}\text { Experiment } \\
\text { method }\end{array}$ & U.S.S & S.S & S.S & S.S & S.S & S.S & S.S \\
\hline Rock type & $\begin{array}{c}\text { Fontainebleau } \\
\text { sand stone }\end{array}$ & $\begin{array}{l}\text { Berea sand } \\
\text { stone }\end{array}$ & $\begin{array}{l}\text { Spynie sand } \\
\text { stone }\end{array}$ & $\begin{array}{l}\text { North Sea } \\
\text { gas } \\
\text { condensate }\end{array}$ & $\begin{array}{l}\text { Berea sand } \\
\text { stone }\end{array}$ & $\begin{array}{l}\text { Berea sand } \\
\text { stone }\end{array}$ & Carbonate \\
\hline Porosity (\%) & 9.9 & 20 & 22 & 17.4 & 18.2 & 19.8 & $15.8^{*}$ \\
\hline $\begin{array}{l}\text { Absolute } \\
\text { permeability } \\
\text { (md) }\end{array}$ & 83 & 193 & 23 & 73.39 & 92 & 92 & 18.56 \\
\hline $\begin{array}{l}\text { Irreducible } \\
\text { water }(\%)\end{array}$ & 0 & 0 & 0 & 0.209 & 26.4 & 26.4 & 0 \\
\hline $\begin{array}{l}\text { Fluid } \\
\text { composition }\end{array}$ & $\mathrm{C} 1-n \mathrm{C} 7$ & C1-C3 & $\mathrm{C} 1-\mathrm{C} 3$ & $\begin{array}{l}\text { North Sea } \\
\text { gas } \\
\text { condensate }\end{array}$ & $\begin{array}{c}\mathrm{C} 1-\mathrm{C} 3-n \mathrm{C} 5- \\
n \mathrm{C} 10-n \mathrm{C} 16\end{array}$ & $\mathrm{C} 1-n \mathrm{C} 4$ & $\mathrm{C} 1-n \mathrm{C} 6$ \\
\hline $\begin{array}{l}\text { Temperature } \\
\left({ }^{\circ} \mathrm{C}\right)\end{array}$ & 71.1 & 21 & 31.7 & 121.1 & - & 37 & - \\
\hline IFT $(\mathrm{mN} / \mathrm{m})$ & $0.001-12.6$ & $0.03-0.83$ & $0.001-0.05$ & $0.03-0.35$ & $0.05-0.4$ & $0.14-0.9$ & $0.01-0.39$ \\
\hline$N_{\mathrm{c}}(\mathrm{e}-6)$ & $0.05-1100$ & $0.443-148$ & $5.56-947$ & $5.36-42.9$ & $9.4-36$ & $0.28-14$ & $0.124-8.62$ \\
\hline
\end{tabular}

$(-)$ : means that data were not reported; $(*)$ : the porosity value was predicted by utilizing correlation proposed by (Timur, 1968) $\left(\emptyset=\sqrt[4.5]{0.136 k s_{\mathrm{wr}}^{2}}\right)$. S.S: steady state, U.S.S: unsteady state.

factors governing the fluid flow in the pore scale. However, the influence of the viscous force increases when the $N_{\mathrm{c}}$ towards unity by an increase in velocity as well as a decrease in IFT. Additionally, the evaluation of the Reynolds number values reveals the governance of the viscous forces in comparison to the inertia. The calculated Re values ranged from $2.93 \mathrm{E}-06$ to $8.72 \mathrm{E}-04$ for all datasets. The critical Reynolds numbers correspond to the 74.8553 , $69.2509,68.1219,69.3634,69.3634,69.3634$, and 71.6003 values for datasets $1-7$, respectively. Although the Re values also increase by an increase in velocity, they are remarkably lower than their critical value in all employed literature datasets. Accordingly, the negative effect of inertia was not detected over the relative permeability points utilized in this study, designating that the flow was within the laminar regime. Additionally, the fluid flow was chiefly governed by the capillary and viscous forces, which supports the aforementioned literature findings.

For fulfilling the scope of the current study, the direct linear interpolation was utilized to predict the relative permeability as a function of saturation (Eq. (5)) and non-wet to wet relative permeability ratio (Eq. (6)). The foregoing correlations use a capillary number dependent weighting factor to predict a certain relative permeably point through its corresponding immiscible and miscible relative permeabilities. A comprehensive regression analysis was carried out by utilizing the above-described datasets to achieve an appropriate mathematical expression for the weighting factor. The analysis led to the capillary dependent logistic function of equation (6). This function represents the interaction between the capillary and viscous forces regardless of the inertia effect due to the governance of the steady laminar flow regime in all employed datasets. In low capillary numbers (high IFT/low velocity), in which the capillary forces are entirely dominant, the weighting factor corresponds to unity. The weighting factor towards zero by increasing the viscous force that arises from an increase in capillary number (low IFT/moderate velocity). As a consequence, the gas and condensate relative permeability curves improve and tend towards the unit slope line. Two discrete reasons emerged from this (Blom and Hagoort, 1998). The viscous force increment may allow a short-cut in pathways that were blocked under capillary force governance. Furthermore, an increase in viscous force may deploy motionless fluids such as isolated blobs, namely the sources of the residual saturation.

Accordingly, the identical weighting factor was employed for linking the residual saturations of the immiscible and miscible conditions. As previously stated, the residual saturation of both phases towards zero by an enhancement in viscous forces. Subsequently, the weighting factor towards zero by the capillary number increment.

The values of the tuning parameters of equation (6) for relative permeability and residual saturation are 
Table 2. The calculated dimensionless numbers over various IFT and velocity values.

\begin{tabular}{|c|c|c|c|c|c|c|}
\hline Dataset & Experiment method & IFT & $v(\mathrm{~m} / \mathrm{s})$ & $N_{\mathrm{c}}$ & $\operatorname{Re}$ & $\operatorname{Re}_{\mathrm{c}}$ \\
\hline $\begin{array}{l}\text { Dataset } 1 \\
\text { (Longeron, 1980) }\end{array}$ & Unsteady state & $\begin{array}{l}0.065 \\
0.040 \\
0.020 \\
0.001\end{array}$ & $\begin{array}{l}5.61 \mathrm{E}-05 \\
5.56 \mathrm{E}-05 \\
5.03 \mathrm{E}-05 \\
5.71 \mathrm{E}-05\end{array}$ & $\begin{array}{l}1.92 \mathrm{E}-04 \\
3.84 \mathrm{E}-04 \\
6.57 \mathrm{E}-03 \\
1.11 \mathrm{E}-02\end{array}$ & $\begin{array}{l}8.57 \mathrm{E}-04 \\
8.49 \mathrm{E}-04 \\
7.68 \mathrm{E}-04 \\
8.72 \mathrm{E}-04\end{array}$ & 74.85532 \\
\hline $\begin{array}{l}\text { Dataset } 2 \text { (Asar } \\
\text { and Handy, 1988) }\end{array}$ & Steady state & $\begin{array}{l}0.830 \\
0.430 \\
0.180 \\
0.030\end{array}$ & $\begin{array}{l}3.61 \mathrm{E}-05 \\
3.82 \mathrm{E}-04 \\
4.13 \mathrm{E}-04 \\
4.41 \mathrm{E}-04\end{array}$ & $\begin{array}{l}2.22 \mathrm{E}-06 \\
4.47 \mathrm{E}-05 \\
1.16 \mathrm{E}-04 \\
7.40 \mathrm{E}-04\end{array}$ & $\begin{array}{l}1.90 \mathrm{E}-05 \\
2.01 \mathrm{E}-04 \\
2.17 \mathrm{E}-04 \\
2.32 \mathrm{E}-04\end{array}$ & 69.25087 \\
\hline $\begin{array}{l}\text { Dataset } 3 \text { (Haniff } \\
\text { and Ali, 1990) }\end{array}$ & Steady state & $\begin{array}{l}0.200 \\
0.100 \\
0.050 \\
0.010 \\
0.001\end{array}$ & $\begin{array}{l}1.07 \mathrm{E}-04 \\
8.55 \mathrm{E}-05 \\
8.71 \mathrm{E}-05 \\
8.96 \mathrm{E}-05 \\
9.12 \mathrm{E}-05\end{array}$ & $\begin{array}{l}2.53 \mathrm{E}-05 \\
4.04 \mathrm{E}-05 \\
8.23 \mathrm{E}-05 \\
4.23 \mathrm{E}-04 \\
4.30 \mathrm{E}-03\end{array}$ & $\begin{array}{c}1.53 \mathrm{E}-05 \\
1.22 \mathrm{E}-05 \\
1.25 \mathrm{E}-05 \\
1.28 \mathrm{E}-05 \\
1.3 \mathrm{E}-05\end{array}$ & 68.12191 \\
\hline $\begin{array}{l}\text { Dataset } 4 \text { (Chen } \\
\text { et al., 1995) }\end{array}$ & Steady state & $0.034-0.349$ & $\begin{array}{l}4.94 \mathrm{E}-06 \\
9.89 \mathrm{E}-06 \\
1.98 \mathrm{E}-05 \\
3.95 \mathrm{E}-05\end{array}$ & $\begin{array}{l}3.08 \mathrm{E}-05 \\
6.16 \mathrm{E}-05 \\
1.23 \mathrm{E}-04 \\
2.46 \mathrm{E}-04\end{array}$ & $\begin{array}{l}1.27 \mathrm{E}-04 \\
2.55 \mathrm{E}-04 \\
5.09 \mathrm{E}-04 \\
1.02 \mathrm{E}-03\end{array}$ & 70.70861 \\
\hline $\begin{array}{l}\text { Dataset } 5 \\
\text { (Henderson et al., } \\
\text { 1997) }\end{array}$ & Steady state & $\begin{array}{l}0.400 \\
0.050\end{array}$ & $\begin{array}{l}1.02 \mathrm{E}-05 \\
9.84 \mathrm{E}-05 \\
4.07 \mathrm{E}-04 \\
1.02 \mathrm{E}-05 \\
9.84 \mathrm{E}-05 \\
4.07 \mathrm{E}-04\end{array}$ & $\begin{array}{l}4.55 \mathrm{E}-06 \\
4.55 \mathrm{E}-05 \\
1.82 \mathrm{E}-04 \\
4.75 \mathrm{E}-05 \\
4.75 \mathrm{E}-04 \\
1.92 \mathrm{E}-03\end{array}$ & $\begin{array}{l}2.93 \mathrm{E}-06 \\
2.83 \mathrm{E}-05 \\
1.17 \mathrm{E}-04 \\
2.93 \mathrm{E}-06 \\
2.83 \mathrm{E}-05 \\
1.17 \mathrm{E}-04\end{array}$ & 69.36340 \\
\hline $\begin{array}{l}\text { Dataset } 6 \\
\text { (Henderson et al., } \\
1988 \text { ) }\end{array}$ & Steady state & 0.140 & $\begin{array}{l}1.07 \mathrm{E}-04 \\
2.14 \mathrm{E}-04 \\
4.28 \mathrm{E}-04 \\
8.56 \mathrm{E}-04 \\
1.07 \mathrm{E}-04 \\
2.14 \mathrm{E}-04 \\
4.28 \mathrm{E}-04 \\
8.56 \mathrm{E}-04\end{array}$ & $\begin{array}{l}1.41 \mathrm{E}-06 \\
2.83 \mathrm{E}-06 \\
5.66 \mathrm{E}-06 \\
1.13 \mathrm{E}-05 \\
9.09 \mathrm{E}-06 \\
1.82 \mathrm{E}-05 \\
3.64 \mathrm{E}-05 \\
7.07 \mathrm{E}-05\end{array}$ & $\begin{array}{l}3.08 \mathrm{E}-05 \\
6.16 \mathrm{E}-05 \\
1.23 \mathrm{E}-04 \\
2.46 \mathrm{E}-04 \\
3.08 \mathrm{E}-05 \\
6.16 \mathrm{E}-05 \\
1.23 \mathrm{E}-04 \\
2.46 \mathrm{E}-04\end{array}$ & 69.36340 \\
\hline $\begin{array}{l}\text { Dataset } 7 \\
\text { (Calisgan and } \\
\text { Akin, 2008) }\end{array}$ & Steady state & $\begin{array}{l}0.3933 \\
0.0590 \\
0.0100\end{array}$ & $\begin{array}{l}2.6556 \mathrm{E}-06 \\
1.3278 \mathrm{E}-06 \\
2.4416 \mathrm{E}-06 \\
1.2192 \mathrm{E}-06 \\
2.3469 \mathrm{E}-06 \\
1.7588 \mathrm{E}-06 \\
1.1734 \mathrm{E}-06\end{array}$ & $\begin{array}{l}5.46 \mathrm{E}-05 \\
5.46 \mathrm{E}-05 \\
5.46 \mathrm{E}-05 \\
5.46 \mathrm{E}-05 \\
5.46 \mathrm{E}-05 \\
5.46 \mathrm{E}-05 \\
5.46 \mathrm{E}-05\end{array}$ & $\begin{array}{l}1.03 \mathrm{E}-05 \\
1.03 \mathrm{E}-05 \\
1.03 \mathrm{E}-05 \\
1.03 \mathrm{E}-05 \\
1.03 \mathrm{E}-05 \\
1.03 \mathrm{E}-05 \\
1.03 \mathrm{E}-05\end{array}$ & 71.60033 \\
\hline
\end{tabular}

represented in Tables 3 and 4, respectively. As can be seen in Table 3, the constant parameters of the logistic function are situated in the limited ranges. According to the author's observations, choosing the default values of $A=2$ and $Q=1$ is not associated with significant errors. Thereby, the value of $B_{i}$ will be situated in the range of $0-0.5$ for both phases. Additionally, for obtaining the exact value of $B_{i}$, its relationship with saturation and multiplication of porosity and permeability was evaluated using regression analysis. The results of the analysis are represented in Figures 2 and 3 for gas and condensate phases, respectively. Two different graphical plots including contour and surface plots are represented to demonstrate the results more descriptively. As it is evident, the tuning parameter of $B_{i}$ 
Table 3. Values of the regression parameters (constants) as well as RMSE and $R^{2}$ entities for the weighting factor of equation $(6)\left(k_{\mathrm{r}}-N_{\mathrm{c}}\right)$ in various datasets used in the current study.

\begin{tabular}{|c|c|c|c|c|c|c|c|c|c|c|}
\hline & \multicolumn{2}{|c|}{$A$} & \multicolumn{2}{|c|}{$Q$} & \multicolumn{2}{|r|}{$B$} & \multicolumn{2}{|c|}{ RMSE } & \multicolumn{2}{|c|}{$R^{2}$} \\
\hline & G & $\mathrm{C}$ & G & $\mathrm{C}$ & G & $\mathrm{C}$ & G & $\mathrm{C}$ & G & $\mathrm{C}$ \\
\hline Dataset 1 & 0.83 & 2.000 & $2.130 \mathrm{E}-5$ & 1.406 & 0.290 & 12.450E-5 & 0.1319 & 0.1378 & 0.8827 & 0.8390 \\
\hline Dataset 2 & 1.028 & 1.000 & 0.025 & 0.016 & 0.100 & 0.099 & 0.1100 & 0.0376 & 0.9447 & 0.9927 \\
\hline Dataset 3 & 2.000 & 2.000 & 0.570 & 0.463 & 0.690 & 0.790 & 0.1132 & 0.0714 & 0.9147 & 0.9710 \\
\hline Dataset 4 & 1.100 & - & 0.500 & - & 0.780 & - & 0.0830 & - & 0.9653 & - \\
\hline Dataset 5 & 2.000 & 2.000 & 1.310 & 1.086 & 0.013 & 0.009 & 0.0958 & 0.0651 & 0.9139 & 0.9652 \\
\hline Dataset 6 & 2.000 & 2.000 & 1.000 & 1.000 & 0.073 & 0.065 & 0.0560 & 0.0721 & 0.9704 & 0.9570 \\
\hline Dataset 7 & 2.000 & - & 1.000 & - & 0.053 & - & 0.0787 & - & 0.9559 & - \\
\hline
\end{tabular}

$(-)$ : means that the data were not reported.

Table 4. Values of the regression parameters (constants) as well as RMSE and $R^{2}$ entities for the weighting factor of equation $(6)\left(S_{\mathrm{r}}-N_{\mathrm{c}}\right)$ in various datasets used in the current study.

\begin{tabular}{|c|c|c|c|c|c|c|c|c|c|c|}
\hline & \multicolumn{2}{|c|}{$A$} & \multicolumn{2}{|c|}{$Q$} & \multicolumn{2}{|c|}{$B$} & \multicolumn{2}{|c|}{ RMSE } & \multicolumn{2}{|c|}{$R^{2}$} \\
\hline & $\mathrm{G}$ & $\mathrm{C}$ & G & $\mathrm{C}$ & G & $\mathrm{C}$ & $\mathrm{G}$ & $\mathrm{C}$ & G & $\mathrm{C}$ \\
\hline Dataset 1 & - & 0.840 & - & 10.000 & - & 1527.820 & - & 0.1198 & - & 0.9228 \\
\hline Dataset 2 & 1.000 & 1.000 & 10.899 & 2.967 & 48.505 & 14.643 & 0.0252 & 0.0301 & 0.9987 & 0.9949 \\
\hline Dataset 3 & 1.198 & 1.000 & 8.846 & 16.857 & 3.785 & 6.369 & 0.0390 & 0.0415 & 0.9946 & 0.9945 \\
\hline Dataset 4 & 1.000 & - & 0.109 & - & 5.746 & - & 0.0003 & - & 0.9991 & - \\
\hline Dataset 5 & 0.938 & 1.000 & 1.823 & 0.915 & 128.026 & 63.131 & 0.0646 & 0.0502 & 0.9653 & 0.9593 \\
\hline Dataset 6 & 0.970 & 1.000 & 0.670 & 0.515 & 24.448 & 6.231 & 0.0382 & 0.0010 & 0.9300 & 0.9999 \\
\hline Dataset 7 & 1.000 & - & 0.880 & - & 0.109 & - & 0.0342 & - & 0.9885 & - \\
\hline
\end{tabular}

$(-)$ : means that the data were not reported.

(a)

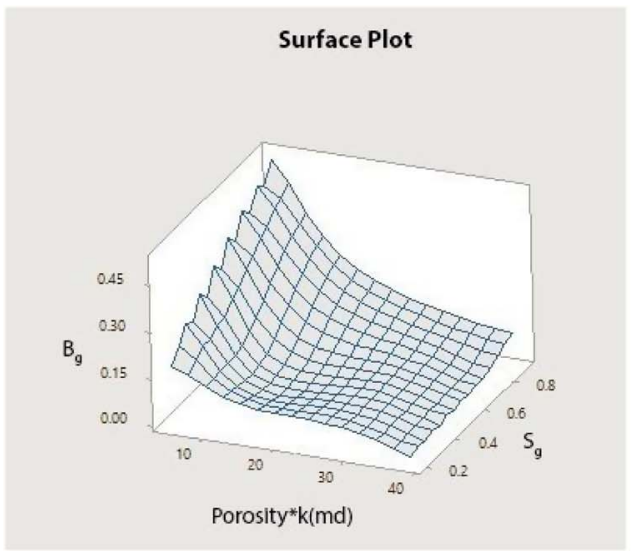

(b)

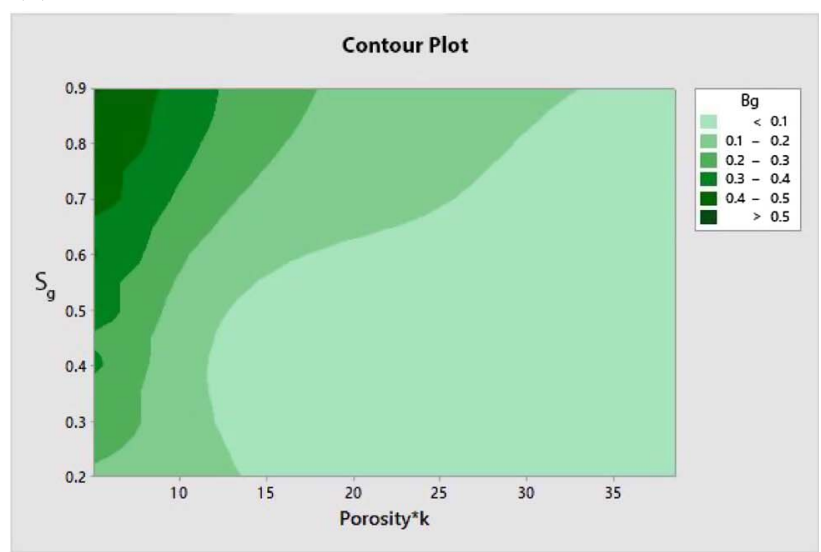

Fig. 2. Employing the (a) surface and (b) contour plots in order to investigate the relationship between $B_{\mathrm{g}}$ (regression parameter of the Eq. (6) for gas), gas saturation and multiplication of the porosity and the permeability (md).

increases by saturation and decreases by the multiplication of porosity and permeability.

\subsection{Validity analysis of the proposed weighting factor}

Accuracy and reliability of the proposed logistic weighting factor were surveyed by employing the Root Mean Square Error (RMSE) and $R$-squared $\left(R^{2}\right)$ statistical parameters. The aforesaid parameters are defined as follows:

$$
\begin{aligned}
\text { RMSE } & =\sqrt{\frac{1}{N} \sum_{i=1}^{N}\left(f_{\exp , i}-f_{\mathrm{pred}, i}\right)^{2},} \\
R^{2} & =1-\frac{\sum_{i=1}^{N}\left(f_{\exp , i}-f_{\mathrm{pred}, i}\right)^{2}}{\sum_{i=1}^{N}\left(f_{\exp , i}-\overline{f_{\exp , i}}\right)^{2}},
\end{aligned}
$$


(a)

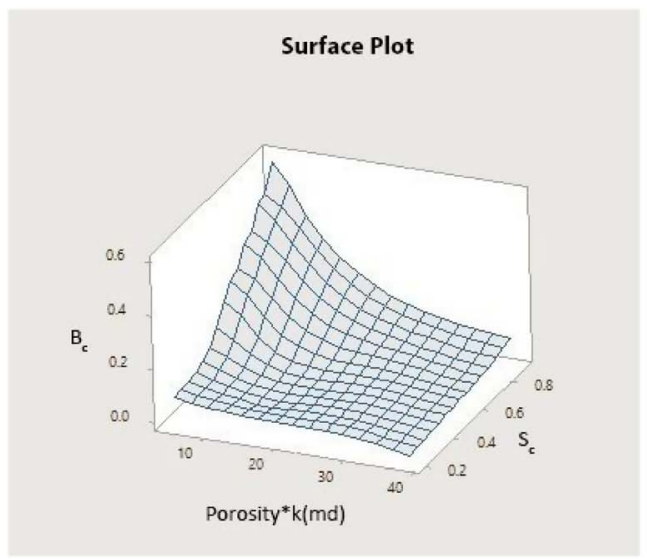

(b)

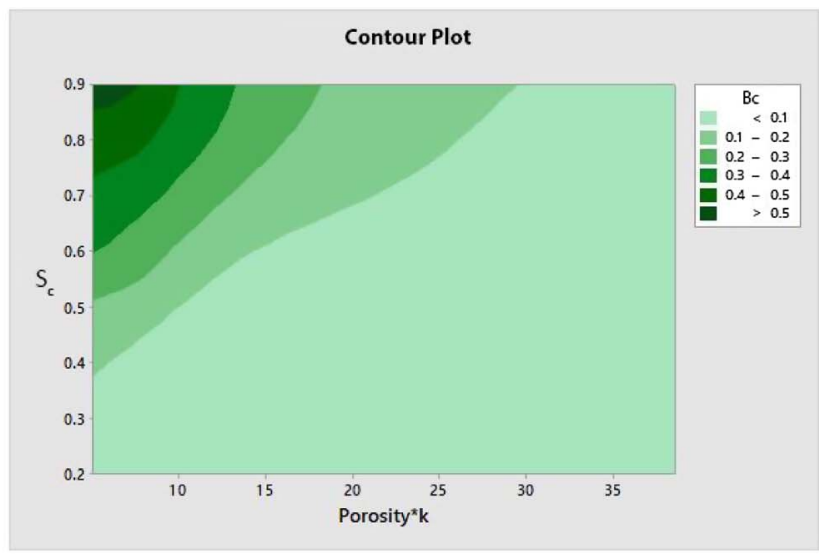

Fig. 3. Employing the (a) surface and (b) contour plots in order to investigate the relationship between $B_{\mathrm{c}}$ (regression parameter of the Eq. (6) for condensate), condensate saturation and multiplication of the porosity and the permeability (md) for the condensate phase.

where, $N$ stands for the number of data points, and the subscripts of exp and pred demonstrate the experimental and predicted values of the weighting factor, respectively.

It is noteworthy that the $R$-squared entity is not an appropriate statistical parameter for investigating the accuracy of the non-linear regressions; however, it was reported habitually in the current study.

The values of the statistical parameters of RMSE and $R^{2}$ for equation (6) are represented in Tables 3 and 4 for relative permeability and residual saturation, respectively. As shown in the tables, this equation represents averagely fair enough accuracy for linking the relative permeability and residual saturation to the capillary number. Furthermore, a visual representation of the results of the regression analysis for developing the weighting factor of equation (6) are shown in Figures 4-7 for relative permeability/residual saturation and gas/condensate phases. The solid points indicate various experimental relative permeability data points, and the solid lines demonstrate the calculated trend using the new correlation. It should be noted that the actual experimental points are capillary number dependent. The weighting factors decrease from 1 to 0 by increasing the capillary number parameter. Furthermore, the experimental points corresponding to the weighting factor of relative permeability are saturation dependent as well as the dependency on the capillary number. However, for the sake of simplicity, the developed weighting factor in this study was linked only to the capillary number parameter. In fact, the maximum achievable accuracy was sacrificed for simplicity. On the other hand, the decreasing trend of weighting factors with the capillary number entity is not unique for all of the datasets. Nevertheless, the proposed weighting factor indicates the ability to fit onto different shapes such as S-shaped and exponential curves. This is another affirmation for the accuracy and reliability of the developed weighting factor in this study.

\subsubsection{Comparison with other literature models}

A comparison was conducted between the proposed weighting factors of equation (6) and the literature proposed equations due to providing further assessment concerning the new model. In this regard, curve fitting analysis was carried out using seven sets of data employed in the current study. Root Mean Square Error (RMSE) and $R$-squared $\left(R^{2}\right)$ statistical parameters were used for determining the accuracy and the fit goodness of the calculated values on the experimental points.

\subsubsection{The weighting factor of equation (6) for relative permeability} The proposed weighting factor of equation (6) was compared with five literature correlations represented in Table 5. As shown in the table, the number of variables of each equation is different from others. The proposed weighting factor of equation (6) as well as equations $f_{1}, f_{2}$ and $\mathrm{f}_{4}$ are only capillary number dependent. However, equations $f_{3}$ and $f_{5}$ are functions of saturation and IFT $(\sigma)$, respectively, together with the capillary number. Results of the comparison are shown in Figures 8 and 9 for gas and condensate phases, respectively. As can be seen, the new weighting factor demonstrates averagely more precision in comparison with other single/two variable equations. Moreover, this logistic function provides enough fitting accuracy consistently in all of the datasets. However, other literature correlations do not indicate uniformly acceptable agreement with the actual experimental points, because they were developed only using a limited number of experimental results. Hence, the developed model in this study provides more reliability for predicting the relative permeability of a gas condensate reservoir, regardless of the type of rock and fluid system.

\subsubsection{The weighting factor of equation (6) for residual saturation} The curve fitting procedure was repeated to investigate the ability of aforesaid expressions for linking the capillary number to the residual saturation. The results of the comparison are shown in Figures 10 and 11 for gas and condensate phases, respectively. As it is evident, the proposed weighting factor of equation (6) indicates more accuracy for both gas and condensate phase than other literature correlations. It should be noted that the $\mathrm{f}_{4}$ 

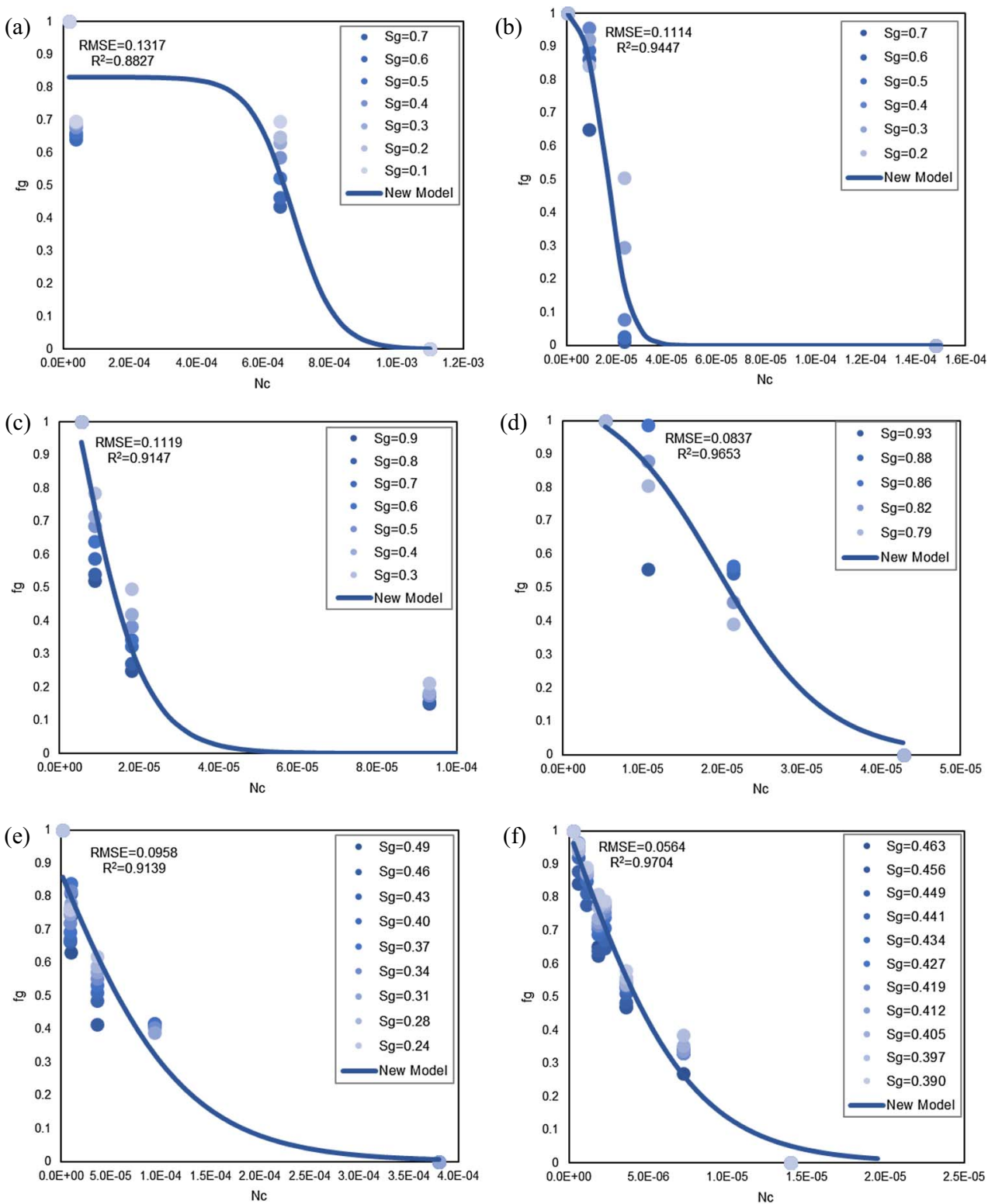

Nc

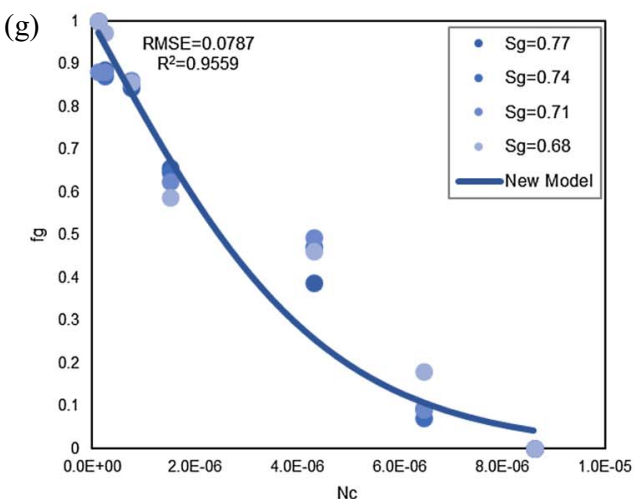

Fig. 4. Investigating the accuracy/precision of the $f_{\mathrm{g}}$ (the proposed weighting factor of Eq. (6) $\left(k_{\mathrm{r}}-N_{\mathrm{c}}\right)$ for the gas phase) for fitting on seven employed literature datasets, namely (a) Dataset 1, (b) Dataset 2, (c) Dataset 3, (d) Dataset 4, (e) Dataset 5, (f) Dataset 6, and (g) Dataset 7 . 
(a)

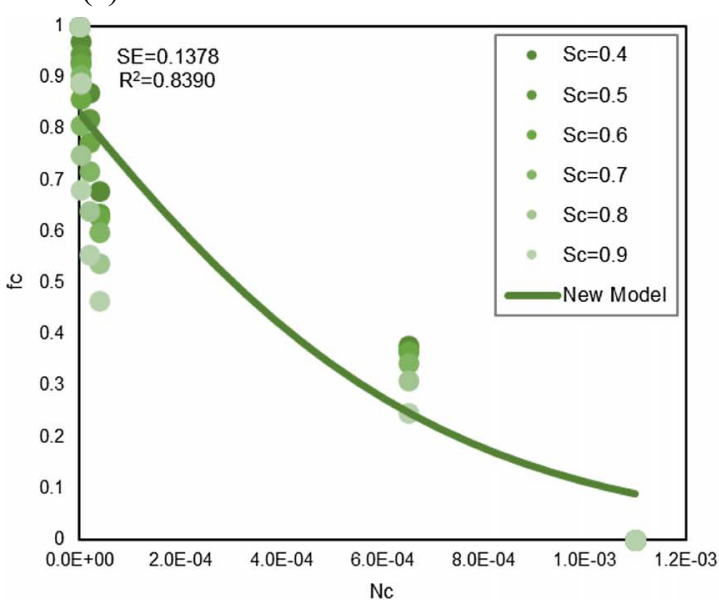

(c)

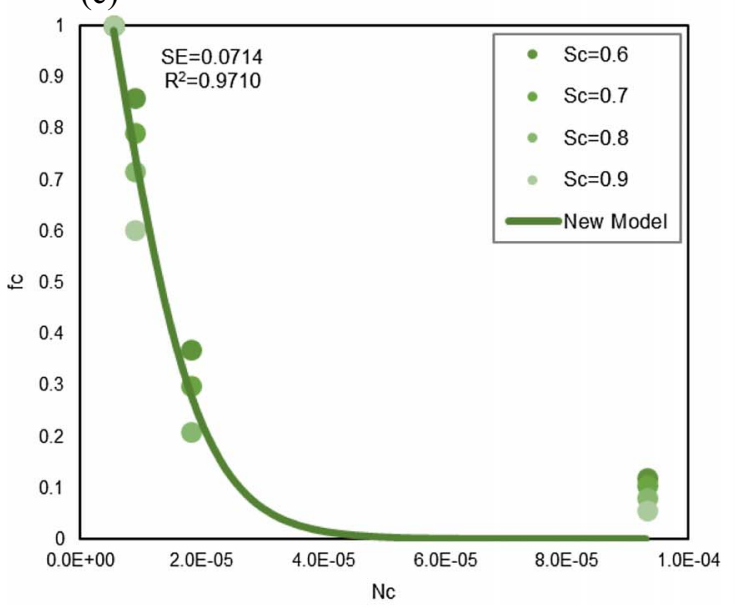

(b)

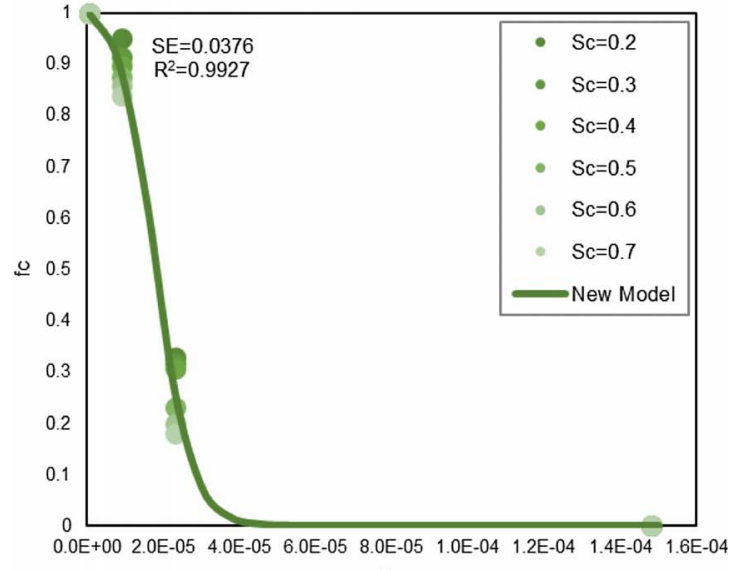

$\mathrm{Nc}$

(d)

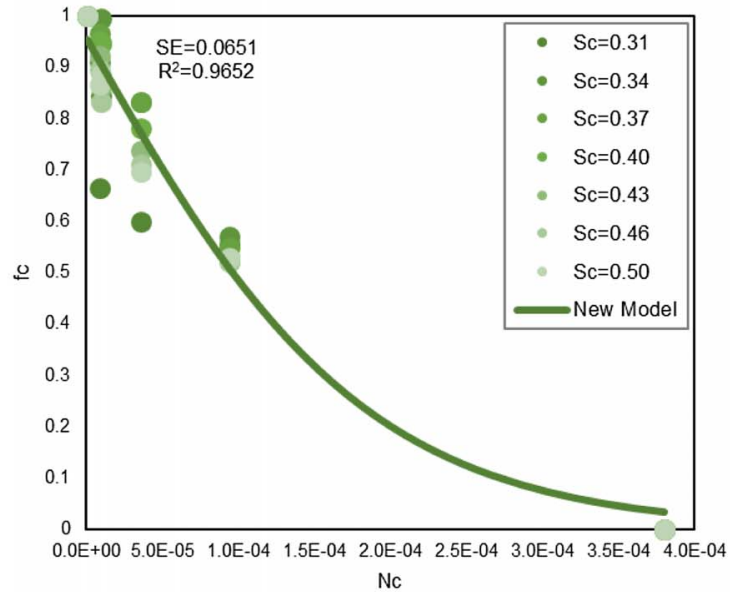

(e)

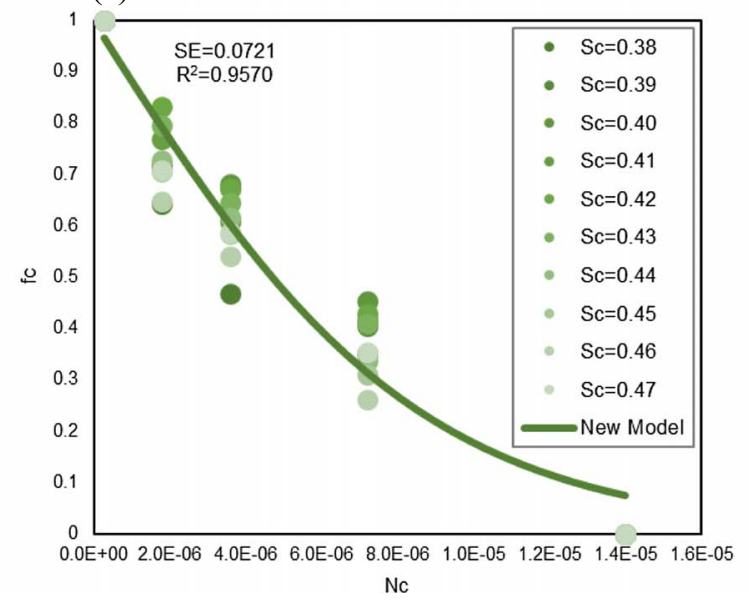

Fig. 5. Investigating the accuracy/precision of the $f_{\mathrm{c}}$ (the proposed weighting factor of Eq. (6) $\left(k_{\mathrm{r}}-N_{\mathrm{c}}\right)$ for the condensate phase) for fitting on five employed literature datasets, namely (a) Dataset 1, (b) Dataset 2, (c) Dataset 3, (d) Dataset 5, and (e) Dataset 6. It should be noted that Datasets 4 and 7 were excluded from the analysis because they were not available for the condensate phase.

weighting factor was not successful for linking the residual saturation to the capillary number; therefore, the values of the statistical parameters of this equation were not reported in the figures.

\subsubsection{Estimation of the relative permeability}

At the end, the proposed model in this study was utilized for the estimation of relative permeability in a gas conden- 
(a)

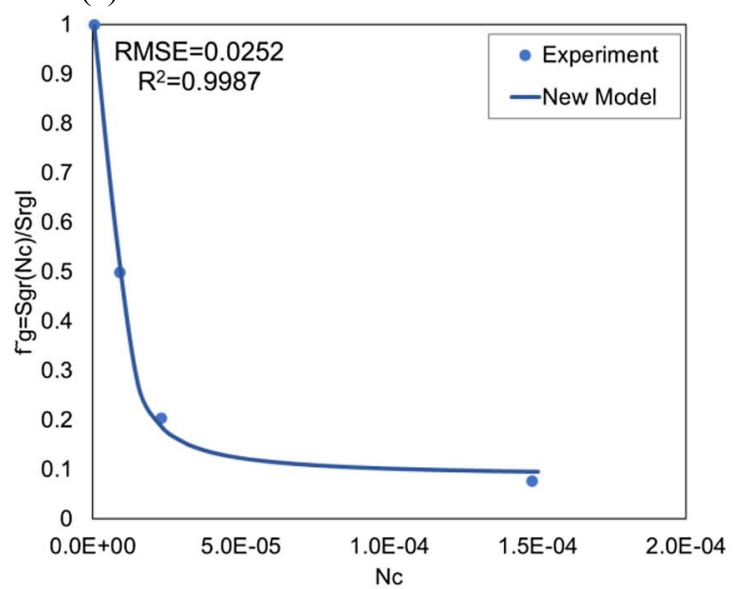

(c)

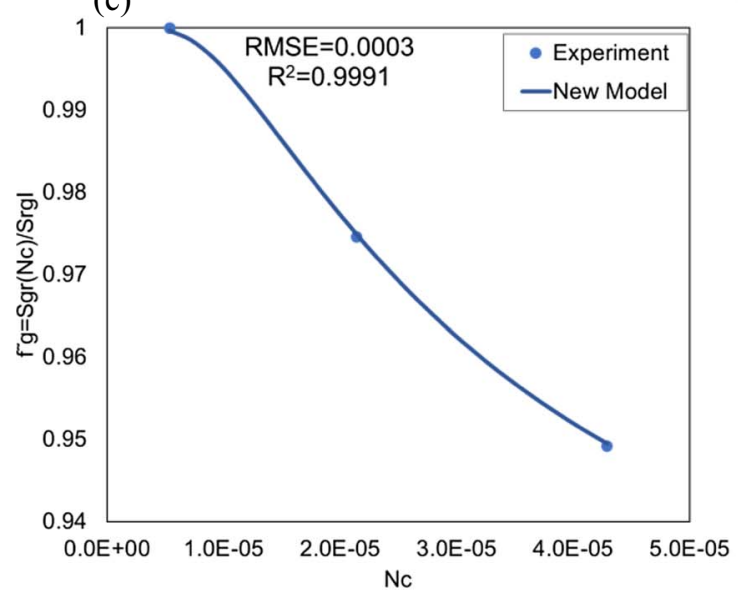

(e)

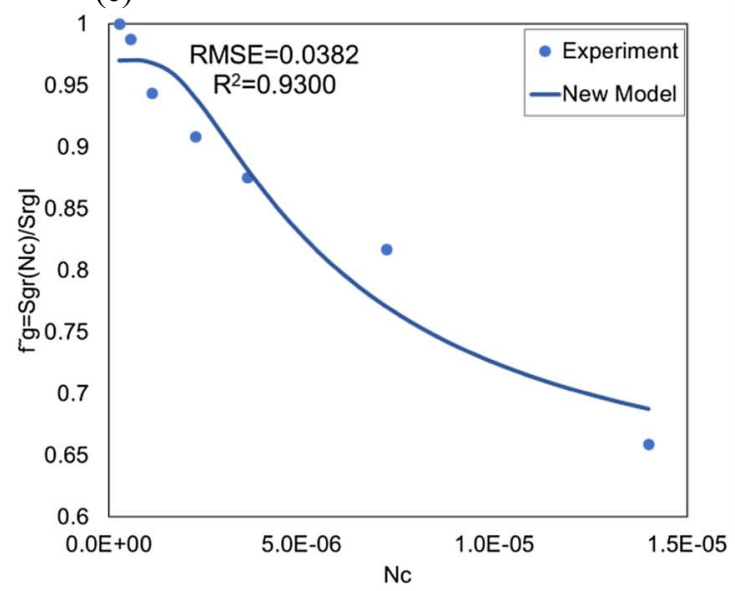

(b)

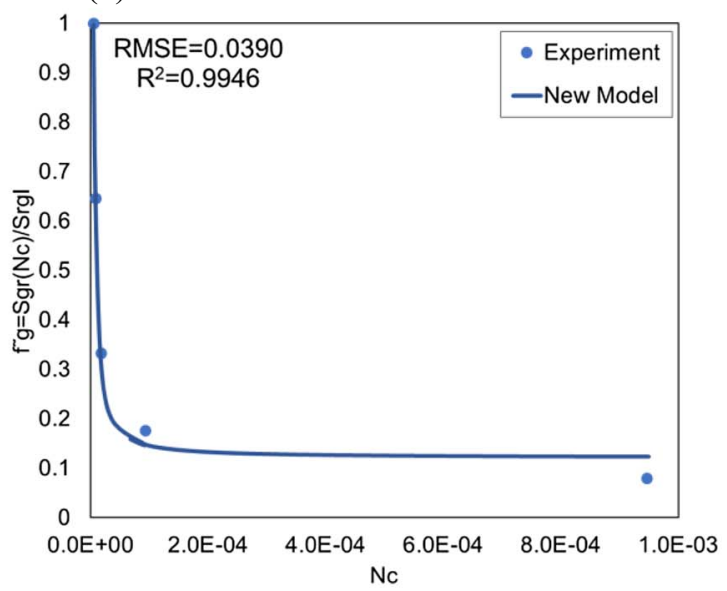

(d)

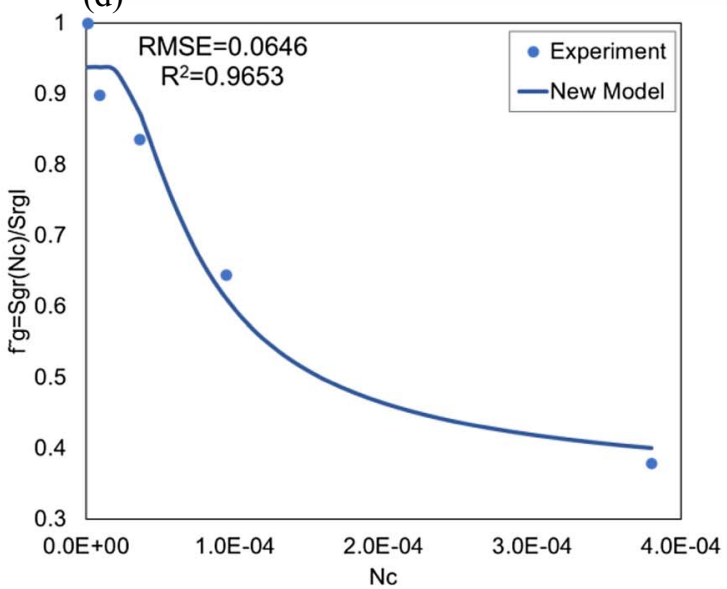

(f)

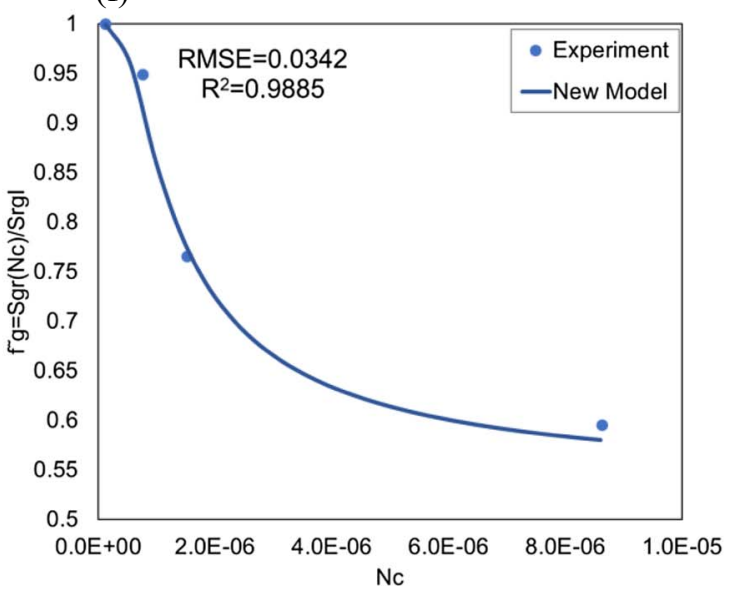

Fig. 6. Investigating the accuracy/precision of the $\tilde{f}_{\mathrm{g}}$ (the proposed weighting factor of Eq. (6) $\left(S_{\mathrm{r}}-N_{\mathrm{c}}\right)$ for the gas phase) for fitting on six employed literature datasets, namely (a) Dataset 2, (b) Dataset 3, (c) Dataset 4, (d) Dataset 5, (e) Dataset 6, and (f) Dataset 7. It should be noted that Dataset 1 was excluded from the analysis because it was not reported for this purpose.

sate reservoir. For this purpose, a recent experimental dataset was adopted from the literature (Blom et al., 1997). These data points were achieved by executing an unsteady-state experiment. The rock system was a glass porous media with porosity and permeability of 0.36 and 972.72 md, respectively. Additionally, the Hexane (as non-wetting phase) and Methanol (as wetting phase) were used as the fluid system of the experiment. The Capillary and Reynolds numbers were calculated at the pore level to recognize the governing flow regime in this dataset. The Capillary number increased from $7.42 \mathrm{E}-4$ to $4.25 \mathrm{E}-2$ by an increase in viscous force dominance. The Reynolds 
(a)

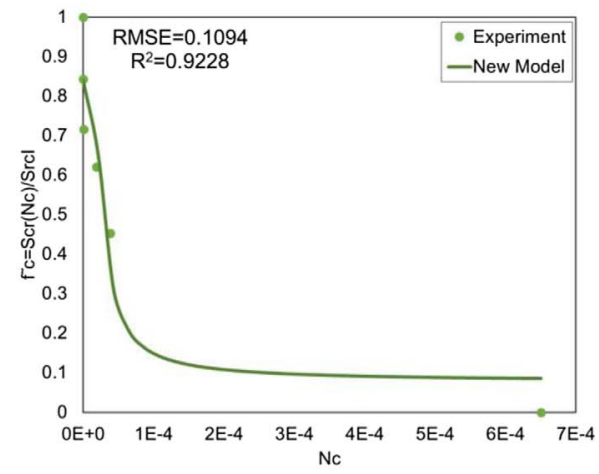

(c)

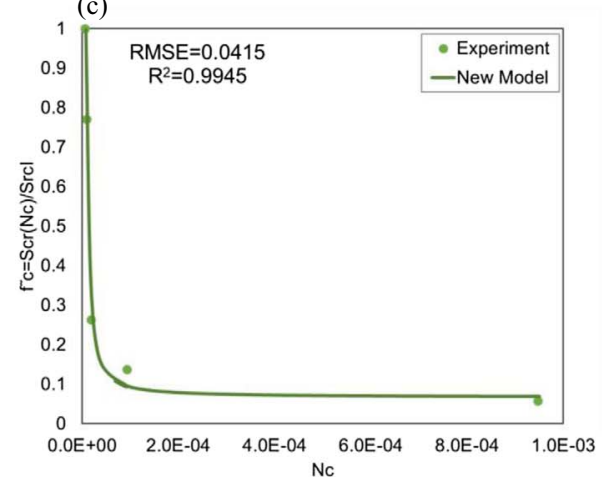

(b)
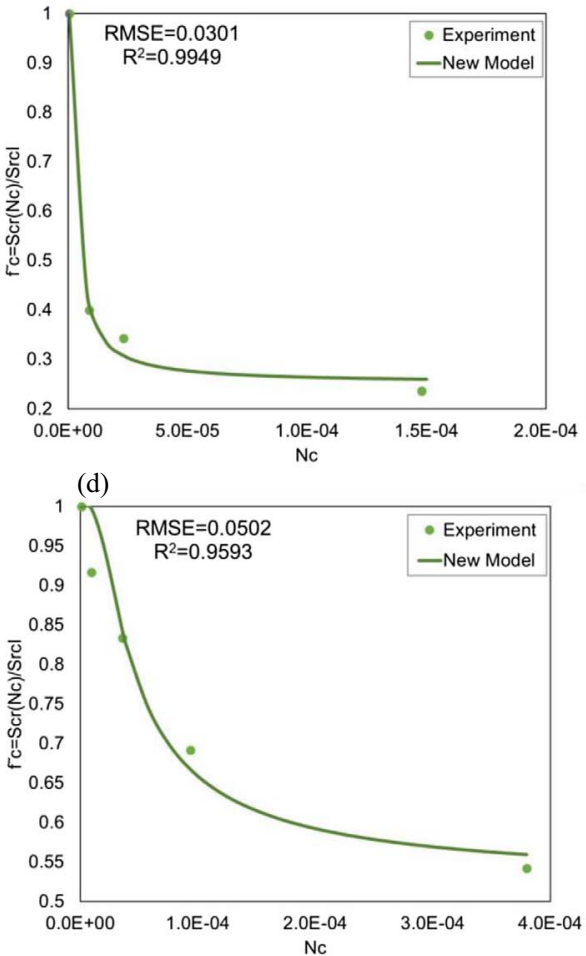

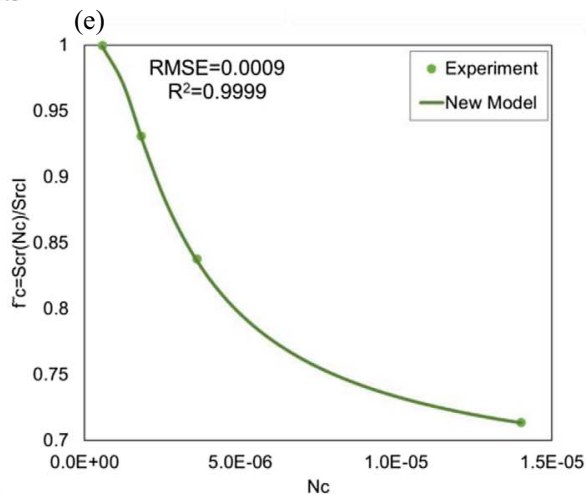

Fig. 7. Investigating the accuracy/precision of the $\tilde{f}_{\mathrm{g}}$ (the proposed weighting factor of Eq. (6) $\left(S_{\mathrm{r}}-N_{\mathrm{c}}\right)$ for the condensate phase) for fitting on five employed literature datasets, namely (a) Dataset 1, (b) Dataset 2, (c) Dataset 3, (d) Dataset 5, and (e) Dataset 6. It should be noted that Datasets 4 and 7 were excluded from the analysis because they were not available for the condensate phase.

Table 5. Five literature published correlations employed for the comparison process.

Authors

Coats (1980)

Nghiem et al. (1981)

Al-Shaidi (1997)

Whitson and Fevang (1997)

Jamiolahmady et al. (2009) $f_{i}$

Equation no.

$$
\left(\frac{N_{\text {cib }}}{N_{\text {ci }}}\right)^{\frac{1}{n_{i}}}
$$

$$
1-e^{-n_{i}\left(\frac{N_{\mathrm{cib}}}{N_{\mathrm{ci}}}\right)}
$$

$$
\left(\frac{N_{\text {cib }}}{N_{\text {ci }}}\right)^{n_{1 i} s_{i}^{-n_{2 i}}}
$$

$$
\frac{1}{\left(n_{1 i} \cdot N_{\mathrm{ci}}\right)^{n_{2 i}}+1}
$$

$$
\frac{1+n_{1 i} \cdot \log \left[\left(\frac{N_{\mathrm{ci}}}{N_{\mathrm{cib}}}\right)\left(\frac{\sigma_{0}}{\sigma}\right)\right]}{1+n_{1 i} \cdot \log \left[\left(\frac{N_{\mathrm{ci}}}{N_{\mathrm{cib}}}\right)\left(\frac{\sigma_{0}}{\sigma}\right)\right]+n_{2 i} \cdot\left\{\log \left[\left(\frac{N_{\mathrm{ci}}}{N_{\mathrm{cib}}}\right)\left(\frac{\sigma_{0}}{\sigma}\right)\right]\right\}^{2}}
$$


(a)

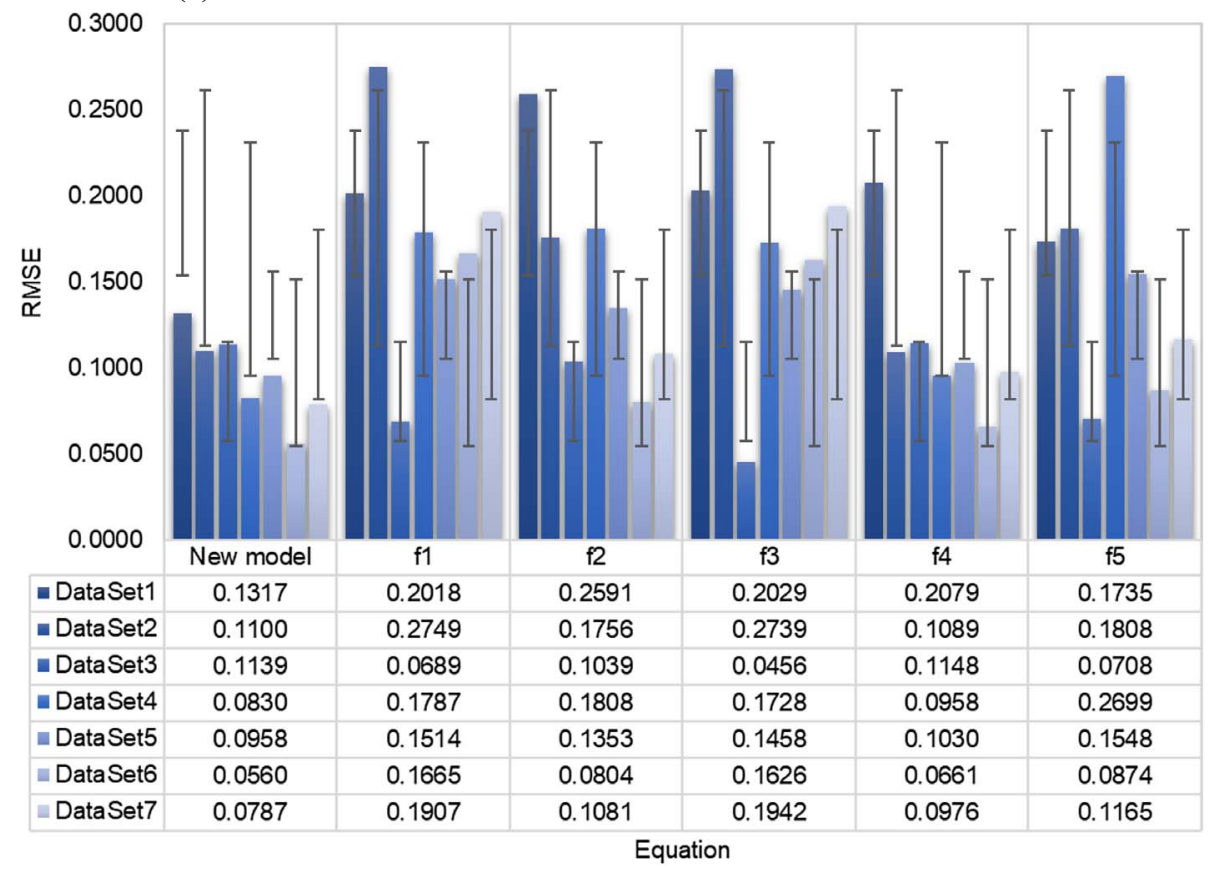

(b)

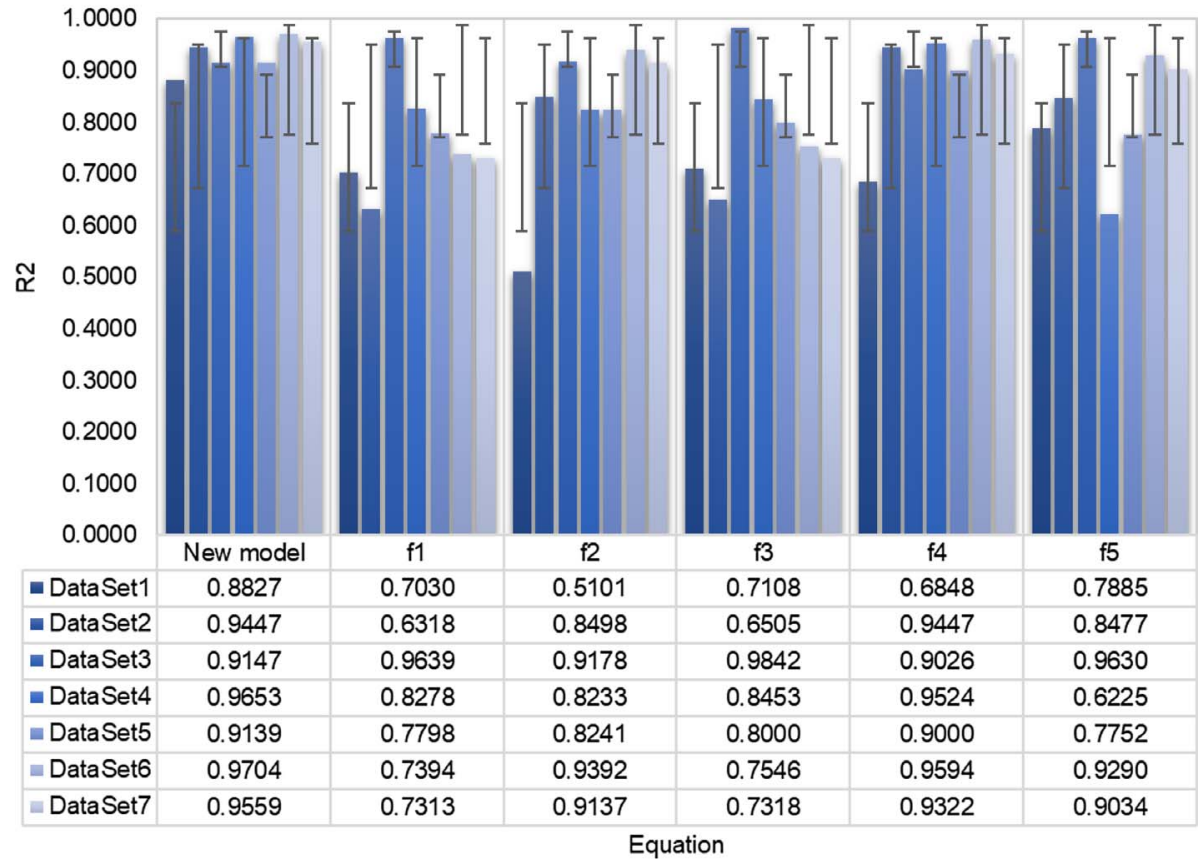

Fig. 8. Comparing the accuracy/precision of the new weighting factor of equation $(6)\left(k_{\mathrm{r}}-N_{\mathrm{c}}\right)$ with five literature published correlations of f1-f5 (Tab. 5) for the gas phase. (a) The RMSE and (b) $R^{2}$ entities were employed for determining the fit goodness of each function on seven experimental datasets of Table 1.

number alters in a range from 0.0019 to 0.0025 , which is much less than the attributed critical Reynolds number of 60.008 . Hence, the entirely laminar flow regime governs the flow behavior.

The procedure of the relative permeability prediction was carried out in accordance with the flowchart of Figure 1. Hence, the direct interpolation of equations (4) and (5) were employed for prediction of $k_{\mathrm{r}}$ as a function of two different sets of inputs, namely $N_{\mathrm{c}}$ and saturation as well as $N_{\mathrm{c}}$ and $k_{\mathrm{rg}} / k_{\mathrm{rc}}$. The experimental relative permeability curves corresponding to capillary numbers of $2.67 \mathrm{E}-4$ and $1.57 \mathrm{E}-2$ were considered as the immiscible and miscible limits, respectively. The proposed default values of the regression parameters of the equation (6) for linking the capillary number to relative permeability ( $A=2$ and $Q=1$ ) were used for curve fitting procedure. Given the velocity ranges utilized in 
(a)

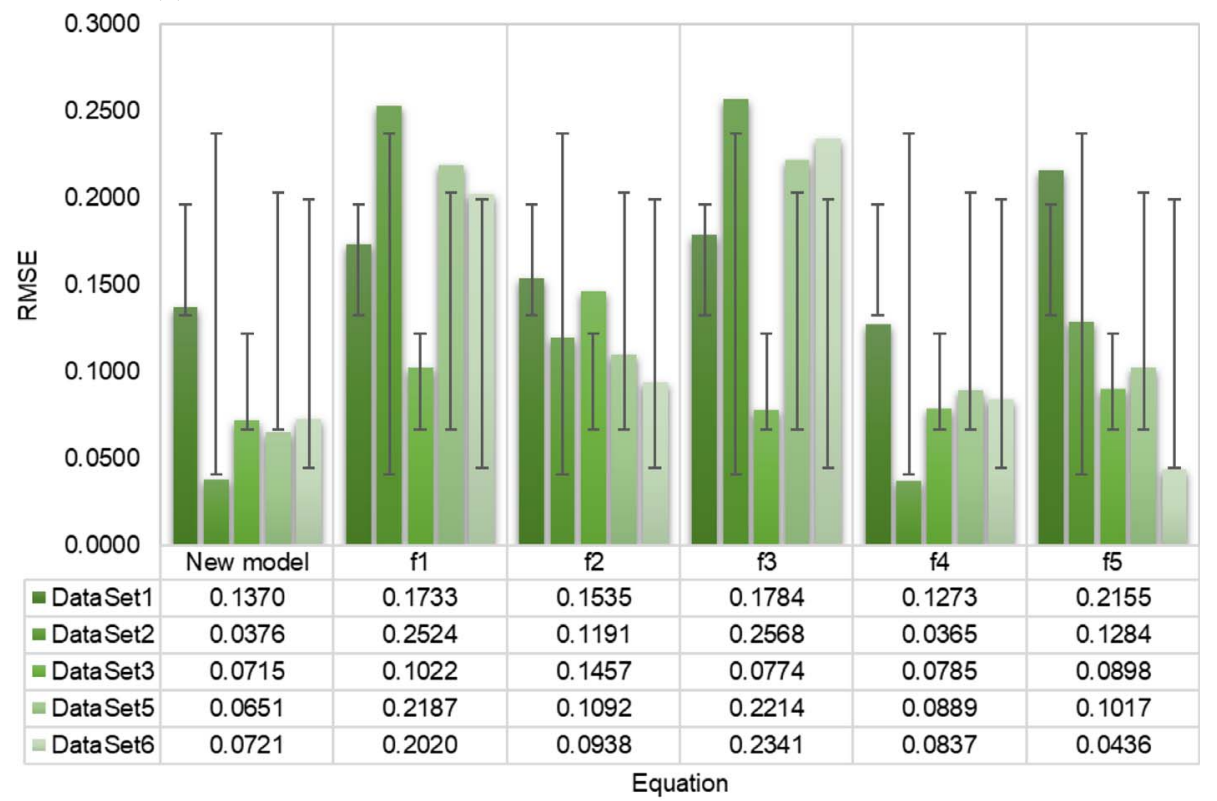

(b)

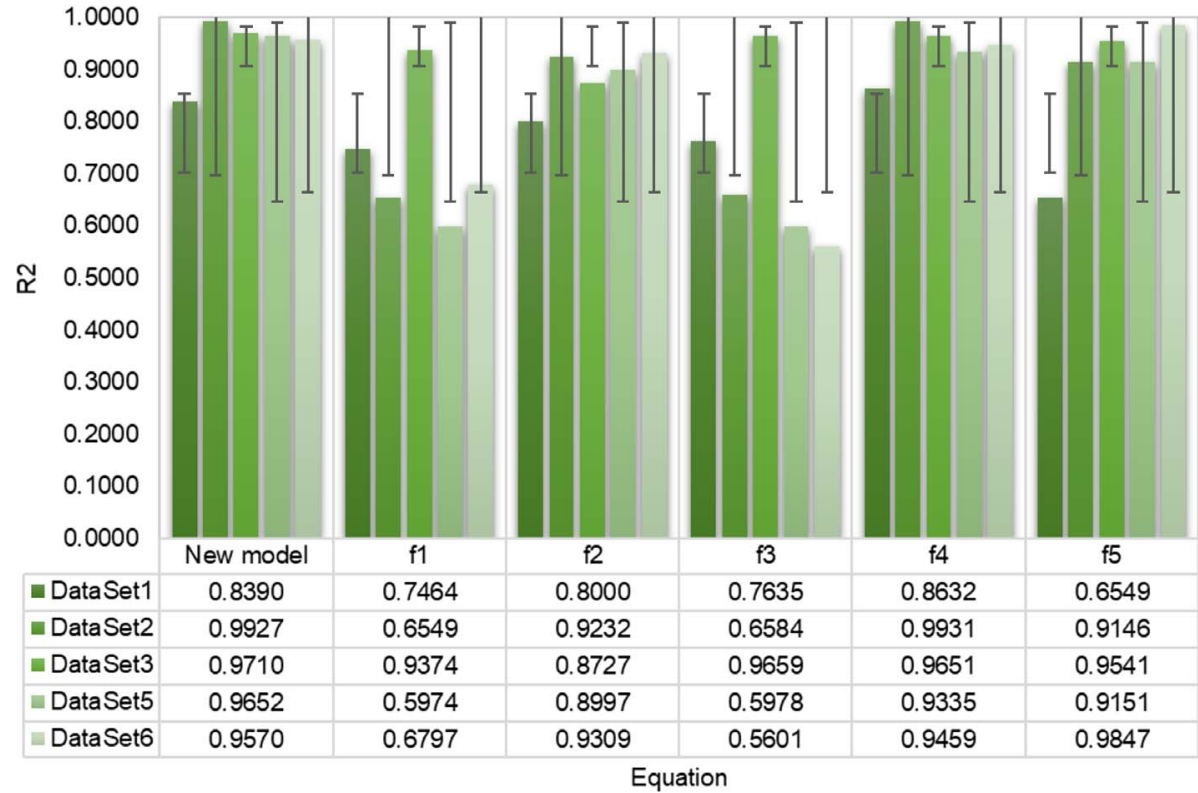

Fig. 9. Comparing the accuracy/precision of the new weighting factor of equation $(6)\left(k_{\mathrm{r}}-N_{\mathrm{c}}\right)$ with five literature published correlations of f1-f5 (Tab. 5) for the condensate phase. (a) The RMSE and (b) $R^{2}$ entities were employed for determining the fit goodness of each function on five experimental datasets of Table 1. It should be noted that Datasets 4 and 7 were excluded from the analysis because they were not available for the condensate phase.

this experiment, the effect of inertia to the relative permeability was not observed; therefore, the effect of inertia was ignored. The accuracy and precision of the model for fitting on the target points were assessed using the statistical parameter of RMSE. Result of the analysis demonstrates the exactitude of equation (4) by the RMSE values of 0.0122 and 0.0418 for gas and condensate phases, respectively. Furthermore, the correctness of the equation (5) is also evident by the appropriate RMSE values of 0.0374 and 0.0049 for gas and condensate phases, respectively. Additionally, the values of the regression parameter of $B_{i}$ were 0.1545 and 0.077 for gas and condensate phases, respectively, which were situated in the default range of $0-0.5$.

A visual description was represented in Figures 12 and 13 to provide more evaluation regarding the weighting functions of equations (4) and (5), respectively. As shown in Figure 12, the proposed model appropriately follows the trend of the relative permeability changes with the $N_{\mathrm{c}}$ and saturation. Furthermore, Figure 13 also demonstrates 
(a)

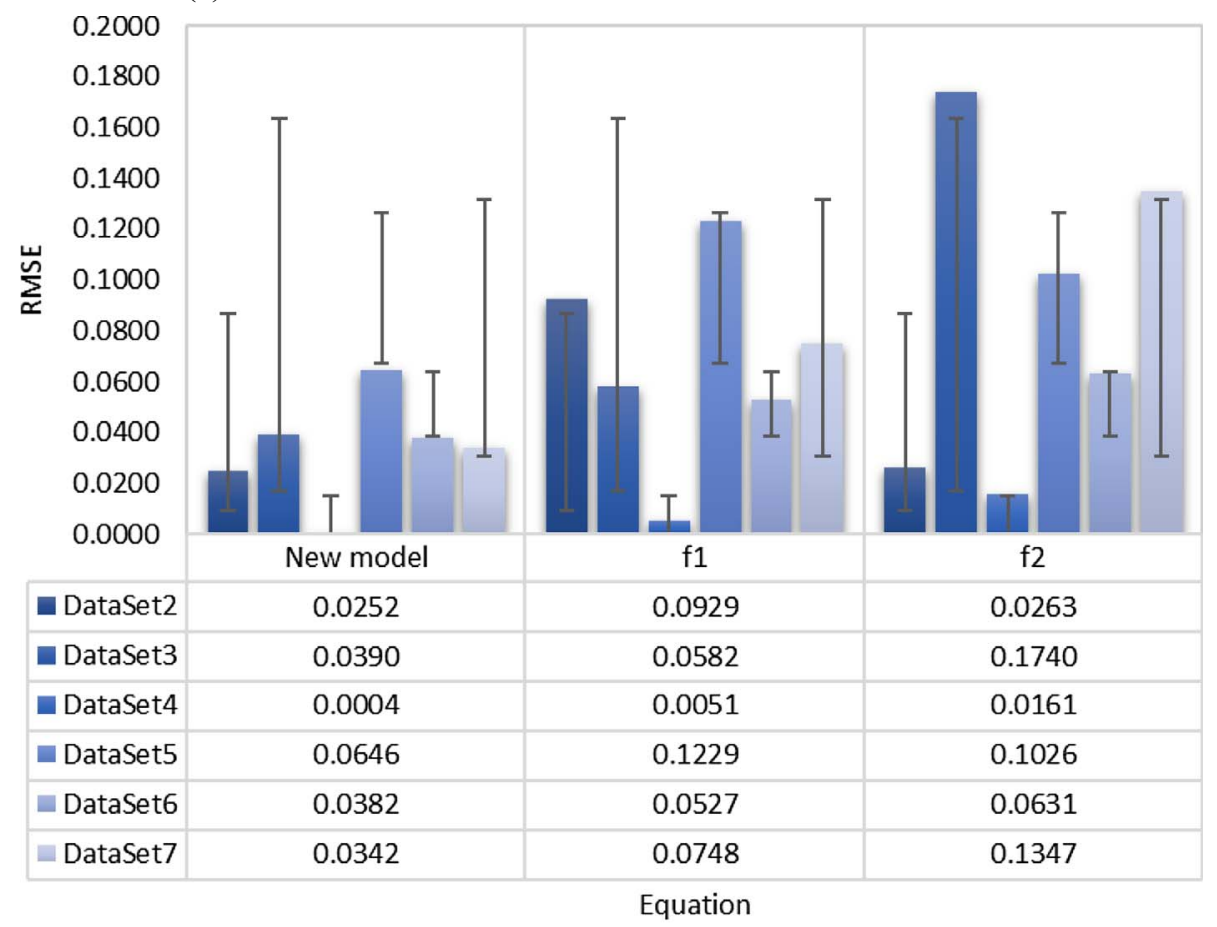

(b)

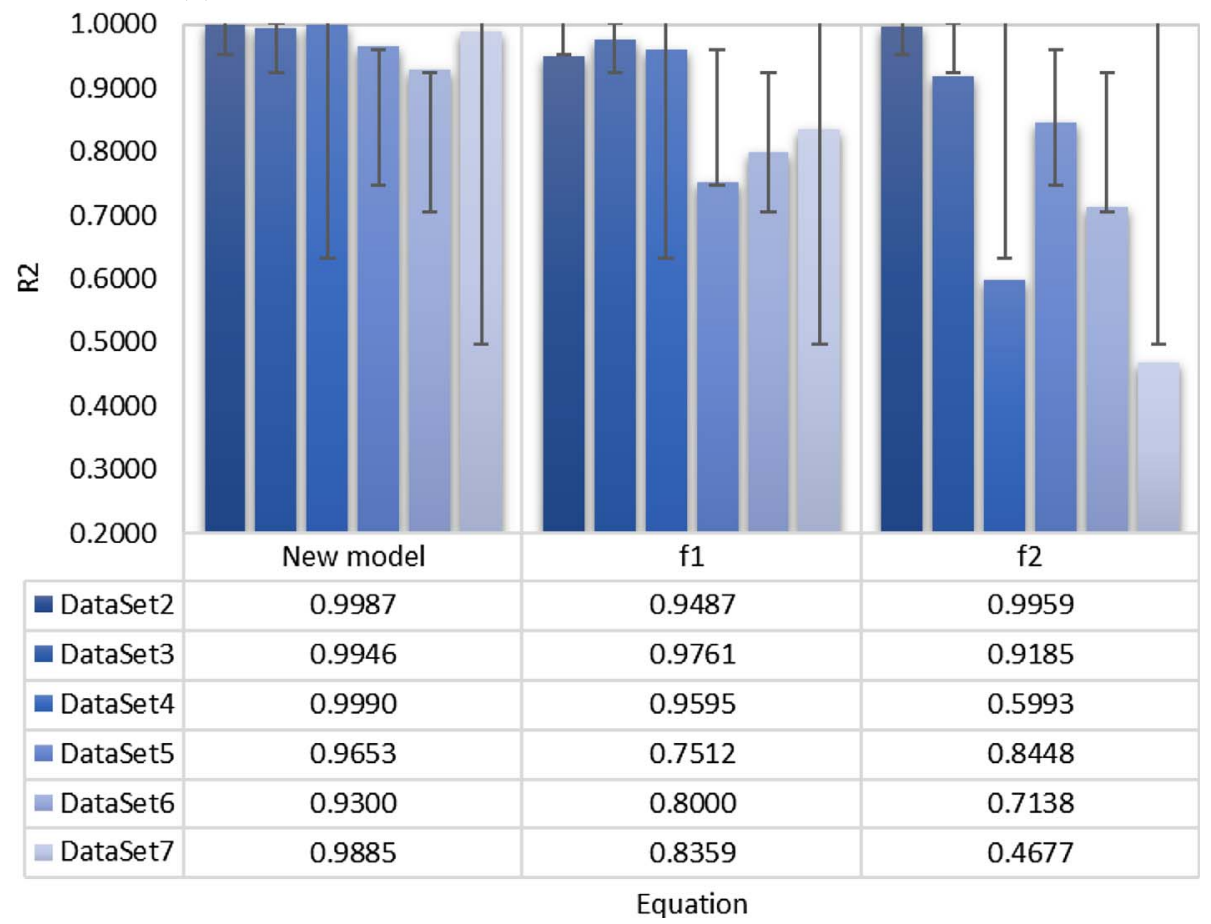

Fig. 10. Comparing the accuracy/precision of the new weighting factor of equation $(6)\left(S_{\mathrm{r}}-N_{\mathrm{c}}\right)$ with literature published correlations of $\mathrm{f} 1$ and $\mathrm{f} 2$ (Tab. 5) for the gas phase. (a) The RMSE and (b) $R^{2}$ entities were employed for determining the fit goodness of each function on six experimental datasets of Table 1. It should be noted that Dataset 1 was excluded from the analysis because it was not reported for this purpose.

that the calculated relative permeability as functions of $N_{\mathrm{c}}$ and $k_{\mathrm{rg}} / k_{\mathrm{rc}}$ congruously accompany the trends of the target points. As can be seen, the gas and condensate relative permeability increases by an increase in the capillary number. Additionally, the influence of the capillary number on the gas relative permeability is more conspicuous. This 
(a)

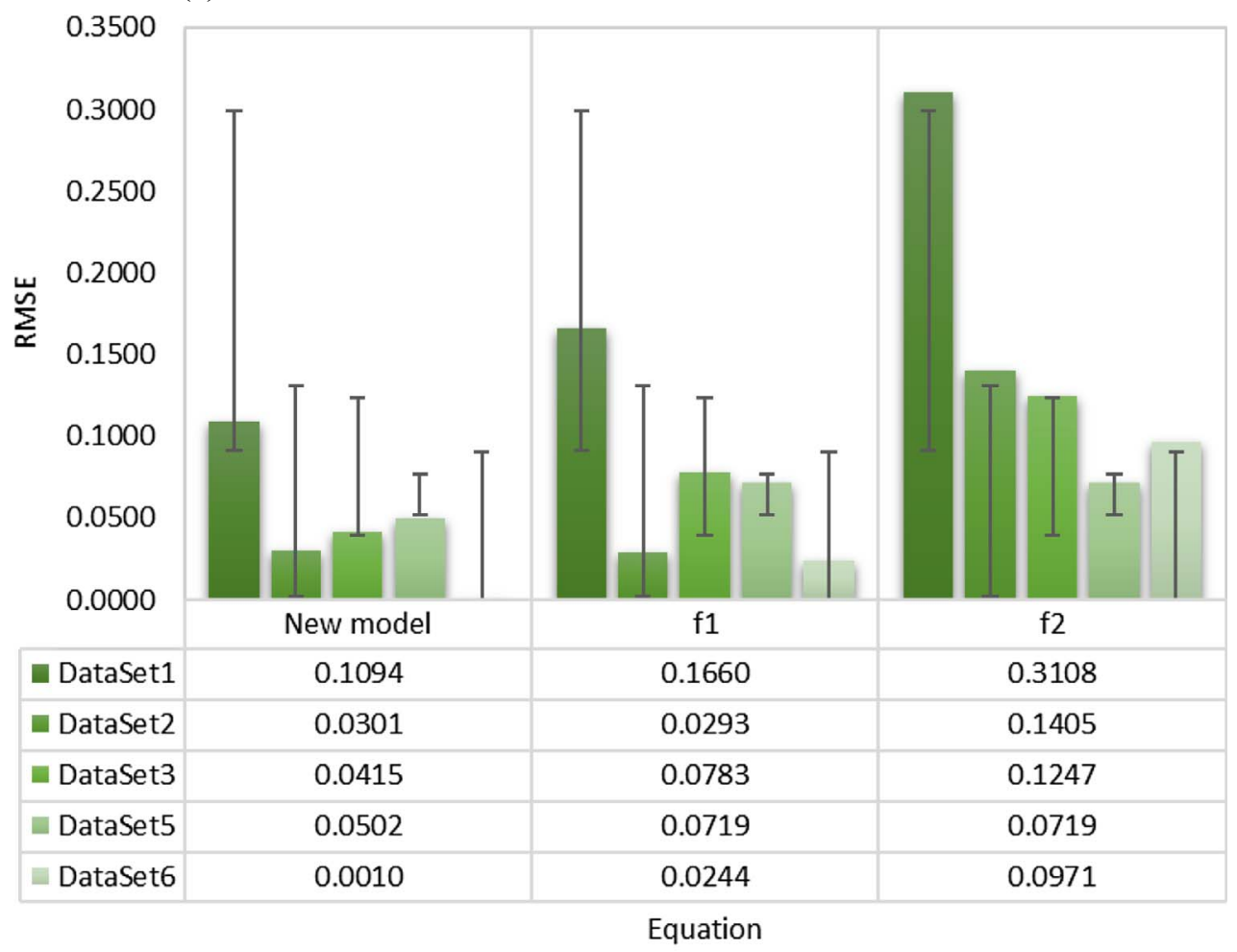

(b)

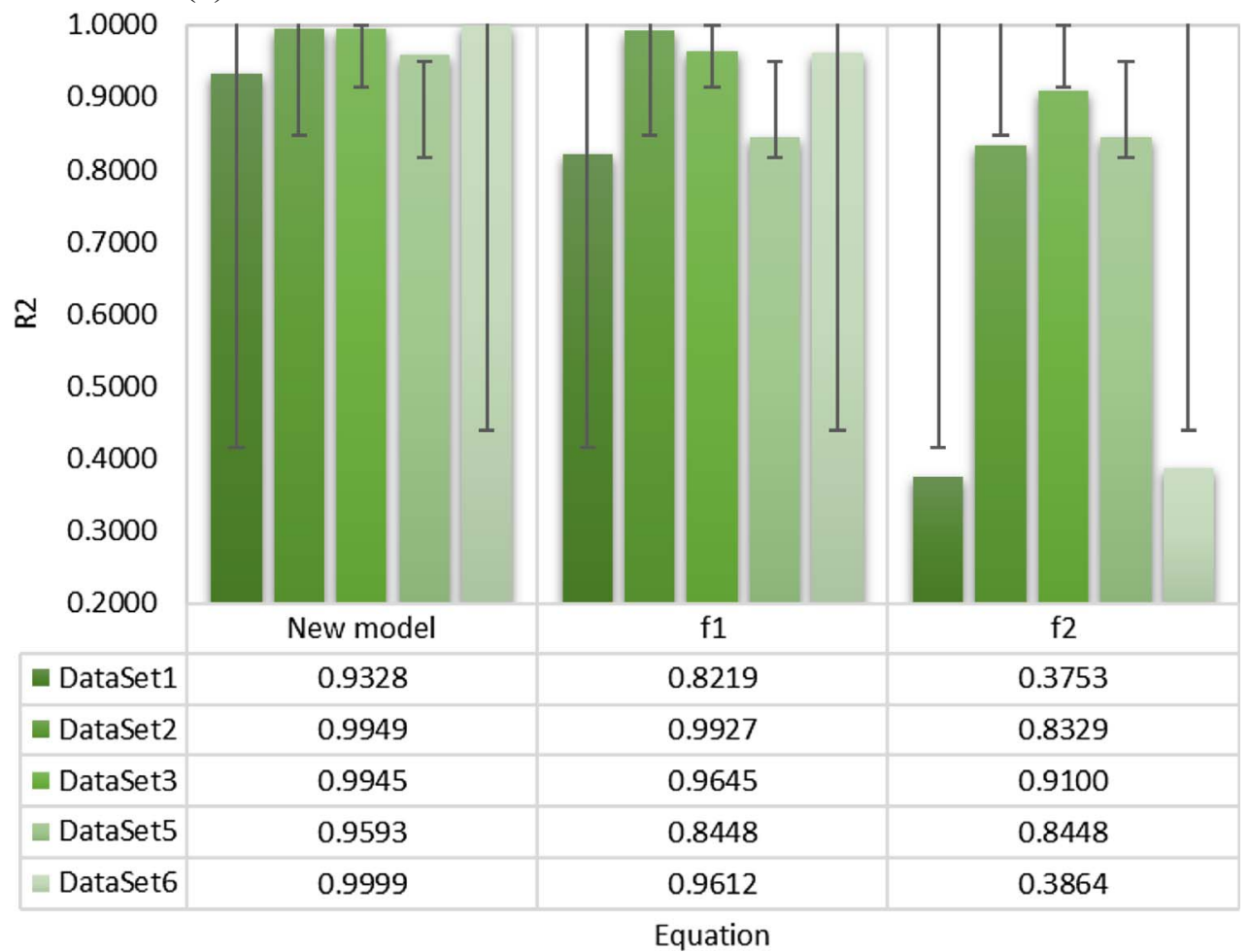

Fig. 11. Comparing the accuracy/precision of the new weighting factor of equation $(6)\left(S_{\mathrm{r}}-N_{\mathrm{c}}\right)$ with literature published correlations of $\mathrm{f} 1$ and $\mathrm{f} 2$ (Tab. 5) for the condensate phase. (a) The RMSE and (b) $R^{2}$ entities were employed for determining the fit goodness of each function on five experimental datasets of Table 1. It should be noted that Datasets 4 and 7 were excluded from the analysis because they were not reported for this purpose. 
(a)

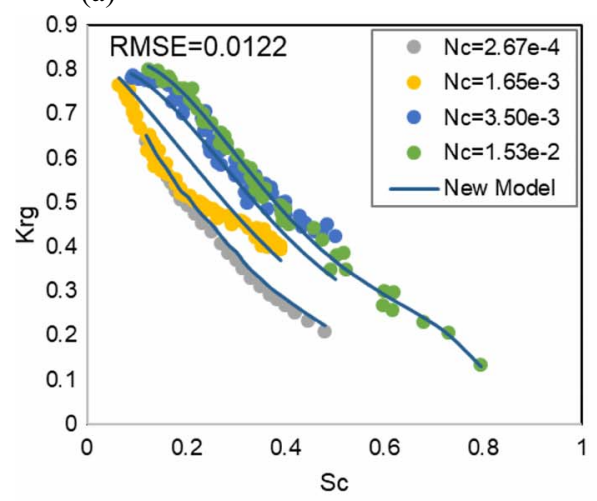

(b)

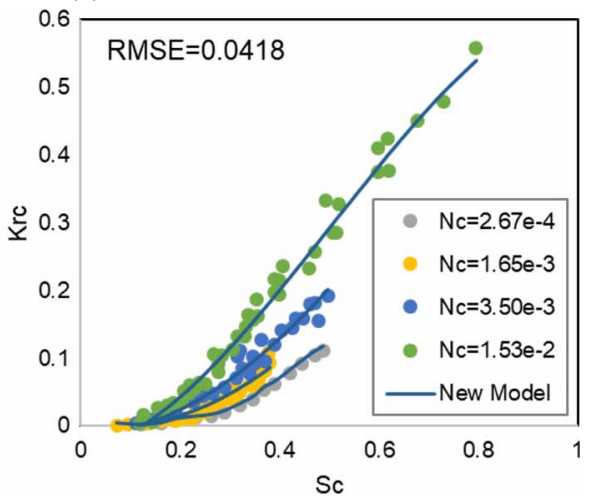

Fig. 12. Investigating the accuracy/precision of the new proposed model for estimation of (a) gas and (b) condensate relative permeabilities as a function of capillary number as well as saturation. The literature published dataset of Blom et al. (1997) was utilized for this purpose.

(a)

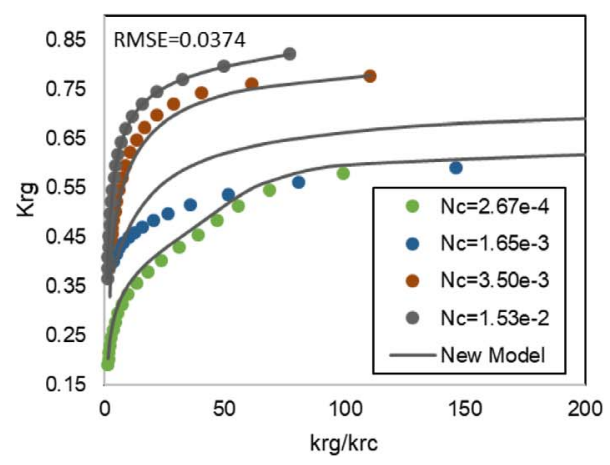

(b)

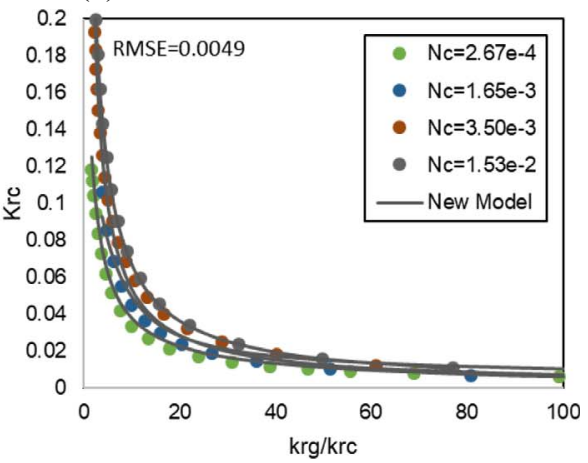

Fig. 13. Investigating the accuracy/precision of the new proposed model for estimation of (a) gas and (b) condensate relative permeabilities as a function of capillary number as well as $k_{\mathrm{rg}} / k_{\mathrm{rc}}$. The literature published dataset of Blom et al. (1997) was utilized for this purpose.

view is not far from reality when alluding to experimental reports of previous studies. It worth pointing out that the residual saturation is not a requirement of relative permeability estimation using equation (5). Consequently, linking the residual saturation to the capillary number is not mandatory when calculating the relative permeability as a function of $k_{\mathrm{rg}} / k_{\mathrm{rc}}$.

\section{Conclusion}

In this paper, a new model was proposed to predict the relative permeability of gas condensate reservoirs. To this end, the direct interpolation approach was utilized for considering both the positive effects of interfacial tension and the low/moderate velocity on the relative permeability. The unique weighting factor of equation (6) was developed to link the relative permeability as well as residual saturation to the capillary number. For this purpose, regression analysis was carried by employing a cumulative number of seven literature published datasets. The accuracy and reliability of the developed correlations were assessed using statistical parameters of RMSE and $R^{2}$. Results of these evaluations are as follows:

1. The proposed weighting factor of equation (6) demonstrates averagely fair enough consistency with experimental data in various rock/fluid systems.

2. A comparison was executed between the developed weighting factor and some literature published correlations. The results of this assessment indicated that the developed correlations in this study outperformed the literature published models from the standpoints of precision and reliability. The recent model benefits from uniformly high enough accuracy for different cases. However, the literature models suffer from high deviations from the target points in some cases.

3. In order to supply more verification, the fit goodness of the proposed model on a recent dataset that has been excluded from the regression procedure was evaluated. The results of the aforesaid assessment represented another affirmation for the validity of the developed model. 


\section{References}

Ahmadi P., Ghandi E., Riazi M., Malayeri M.R. (2019) Experimental and CFD studies on determination of injection and production wells location considering reservoir heterogeneity and capillary number, Oil Gas Sci. Technol. - Rev. IFP Energies nouvelles 74, 4.

Al-Shaidi S.M. (1997) Modelling of gas-condensate flow in reservoir at near wellbore conditions, Heriot-Watt University, Edinburgh, UK.

Amaefule J.O., Handy L.L. (1982) The effect of interfacial tensions on relative oil/water permeabilities of consolidated porous media, Soc. Pet. Eng. J. 22, 3, 371-381. doi: 10.2118/9783-PA.

App J.F., Burger J.E. (2009) Experimental determination of relative permeabilities for a rich gas/condensate system using live fluid, SPE Reserv. Evalu. Eng. 12, 2, 263-269. doi: 10.2118/109810-PA.

Asar H., Handy L.L. (1988) Influence of interfacial tension on gas/oil relative permeability in a gas-condensate system, SPE Reserv. Eng. 3, 1, 257-264.

Avraam D.G., Payatakes A.C. (1995) Flow regimes and relative permeabilities during steady-state two-phase flow in porous media, J. Fluid Mech. 293, 207-236. doi: 10.1017/ S0022112095001698.

Bear J. (2013) Dynamics of fluids in porous media, Courier Corporation, Chelmsford, MA.

Betté S., Hartman K., Heinemann R. (1991) Compositional modeling of interfacial tension effects in miscible displacement processes, J. Pet. Sci. Eng. 6, 1, 1-14.

Blom S., Hagoort J. (1998) How to include the capillary number in gas condensate relative permeability, in: Paper Presented at the SPE Annual Technical Conference and Exhibition, 27-30 September, New Orleans, Louisiana.

Blom S., Hagoort J., Soetekouw D. (1997) Relative permeability at near-critical conditions, in: Paper Presented at the SPE Annual Technical Conference and Exhibition, 5-8 October, San Antonio, Texas.

Brooks R., Corey A. (1964) Hydraulic properties of porous media, Colorado State University, Fort Collins, CO, Hydro Paper, 3, 27 p.

Calisgan H., Akin S. (2008) Near critical gas condensate relative permeability of carbonates, Open Pet. Eng. J. 1, 1, 30-41.

Chen H., Wilson S., Monger-McClure T. (1995) Determination of relative permeability and recovery for North Sea gas condensate reservoirs, in: Paper Presented at the SPE Annual Technical Conference and Exhibition, 22-25 October, Dallas, Texas.

Chukwudeme E.A., Fjelde I., Abeysinghe K.P., Lohne A. (2014) Effect of interfacial tension on water/oil relative permeability on the basis of history matching to coreflood data, SPE Reserv. Evalu. Eng. 17, 1, 37-48.

Coats K.H. (1980) An equation of state compositional model, Soc. Pet. Eng. J. 20, 5, 363-376. doi: 10.2118/8284-PA.

Delshad M., Bhuyan D., Pope G., Lake L. (1986) Effect of capillary number on the residual saturation of a three-phase micellar solution, in: Paper Presented at the SPE Enhanced Oil Recovery Symposium, 20-23 April, Tulsa, Oklahoma.

Delshad M., Najafabadi N.F., Anderson G., Pope G.A., Sepehrnoori K. (2009) Modeling wettability alteration by surfactants in naturally fractured reservoirs, SPE Reserv. Evalu. Eng. 12, 3, 361-370. doi: 10.2118/100081-PA.

Du Plessis J.P., Woudberg S. (2008) Pore-scale derivation of the Ergun equation to enhance its adaptability and generalization, Chem. Eng. Sci. 63, 9, 2576-2586.
Dybbs A., Edwards R. (1984) A new look at porous media fluid mechanics - Darcy to turbulent, in: Fundamentals of transport phenomena in porous media, Springer, Berlin, Germany, pp. 199-256.

Fan L., Harris B.W., Jamaluddin A., Kamath J., Mott R., Pope G.A., Whitson C.H. (2005) Understanding gascondensate reservoirs, Oilfield Rev. 17, 4, 14-27.

Foster W. (1973) A low-tension waterflooding process, J. Pet. Technol. 25, 2, 205-210.

Fulcher R.A. Jr., Ertekin T., Stahl C.D. (1985) Effect of capillary number and its constituents on two-phase relative permeability curves, J. Pet. Technol. 37, 2, 249-260.

Guo H., Dou M., Hanqing W., Wang F., Yuanyuan G., Yu Z., Yansheng W., Li Y. (2015) Review of capillary number in chemical enhanced oil recovery, in: Paper Presented at the SPE Kuwait Oil and Gas Show and Conference, 11-14 October, Mishref, Kuwait. doi: 10.2118/175172-MS.

Haniff M., Ali J. (1990) Relative permeability and low tension fluid flow in gas condensate systems, in: Paper Presented at the European Petroleum Conference, 21-24 October, The Hague, The Netherlands.

Henderson G.D., Danesh A., Al-kharusi B., Tehrani D. (2000a) Generating reliable gas condensate relative permeability data used to develop a correlation with capillary number, J. Pet. Sci. Eng. 25, 1-2, 79-91.

Henderson G., Danesh A., Tehrani D., Al-Kharusi B. (2000b) The relative significance of positive coupling and inertial effects on gas condensate relative permeabilities, in: Paper Presented at the SPE Annual Technical Conference and Exhibition, 1-4 October, Dallas, Texas.

Henderson G., Danesh A., Tehrani D., Al-Shaidi S., Peden J. (1988) Measurement and correlation of gas condensate relative permeability by the steady-state method, SPE Reserv. Evalu. Eng. 1, 2, 134-140.

Henderson G., Danesh A., Tehrani D., Peden J. (1997) The effect of velocity and interfacial tension on relative permeability of gas condensate fluids in the wellbore region, J. Pet. Sci. Eng. 17, 3-4, 265-273.

Jamiolahmady M., Danesh A., Tehrani D.H., Sohrabi M. (2006) Variations of gas/condensate relative permeability with production rate at near-wellbore conditions: A general correlation, SPE Reserv. Evalu. Eng. 9, 6, 688-697. doi: 10.2118/83960-PA.

Jamiolahmady M., Sohrabi M., Ireland S. (2008) Gascondensate relative permeabilities in propped fracture porous media: Coupling vs. Inertia, in: Paper Presented at the SPE Annual Technical Conference and Exhibition, 21-24 September, Denver, Colorado.

Jamiolahmady M., Sohrabi M., Ireland S., Ghahri P. (2009) A generalized correlation for predicting gas-condensate relative permeability at near wellbore conditions, J. Pet. Sci. Eng. 66, 3-4, 98-110.

Johannesen E.B., Graue A. (2007) Mobilization of remaining oil emphasis on capillary number and wettability, in: Paper Presented at the International Oil Conference and Exhibition in Mexico, 27-30 June, Veracruz, Mexico. doi: 10.2118/108724-MS.

Kalla S., Leonardi S.A., Berry D.W., Poore L.D., Sahoo H., Kudva R.A., Braun E.M. (2014) Factors that affect gascondensate relative permeability, in: Paper Presented at the IPTC 2014 International Petroleum Technology Conference, 19-22 January, Doha, Qatar.

Lenormand R., Touboul E., Zarcone C. (1988) Numerical models and experiments on immiscible displacements in porous media, J. Fluid Mech. 189, 165-187. 
Lomeland F., Ebeltoft E., Thomas W.H. (2005) A new versatile relative permeability correlation, in: Paper Presented at the International Symposium of the Society of Core Analysts, 21-25 August, Toronto, Canada.

Longeron D. (1980) Influence of very low interfacial tensions on relative permeability, Soc. Pet. Eng. J. 20, 5, 391-401.

Mott R., Cable A., Spearing M. (1999) A new method of measuring relative permeabilities for calculating gas-condensate well deliverability, in: Paper Presented at the SPE Annual Technical Conference and Exhibition, 3-6 October, Houston, Texas.

Nghiem L.X., Fong D., Aziz K. (1981) Compositional modeling with an equation of state (includes associated papers 10894 and 10903), Soc. Pet. Eng. J. 21, 6, 687-698.

Payatakes A. (1982) Dynamics of oil ganglia during immiscible displacement in water-wet porous media, Annu. Rev. Fluid Mech. 14, 1, 365-393.

Pope G.A., Wu W., Narayanaswamy G., Delshad M., Sharma M.M., Wang P. (2000) Modeling relative permeability effects in gas-condensate reservoirs with a new trapping model, SPE Reserv. Evalu. Eng. 3, 2, 171-178. doi: 10.2118/ 62497-PA.

Stone H.L. (1973) Estimation of three-phase relative permeability and residual oil data, J. Can. Pet. Technol. 12, 4, 53-61.

Timur A. (1968) An investigation of permeability, porosity, and residual water saturation relationships for sandstone reservoirs, Log Anal. 9, 4, 3-5.
Tsakiroglou C.D. (2019) The correlation of the steady-state gas/ water relative permeabilities of porous media with gas and water capillary numbers, Oil Gas Sci. Technol. - Rev. IFP Energies nouvelles 74, 45.

Tsakiroglou C.D., Aggelopoulos C.A., Terzi K., Avraam D.G., Valavanides M.S. (2015) Steady-state two-phase relative permeability functions of porous media: A revisit, Int. $J$. Multiph. Flow 73, 34-42.

Tsakiroglou C.D., Avraam D.G., Payatakes A.C. (2007) Transient and steady-state relative permeabilities from two-phase flow experiments in planar pore networks, Adv. Water Res. 30, 9, 1981-1992. doi: 10.1016/j.advwatres.2007.04.002.

Urumović K., Urumović K. Sr. (2016) The referential grain size and effective porosity in the Kozeny-Carman model, Hydrol. Earth Syst. Sci. 20, 5, 1669-1680.

van Lopik J.H., Snoeijers R., van Dooren T.C., Raoof A., Schotting R.J. (2017) The effect of grain size distribution on nonlinear flow behavior in sandy porous media, Transp. Porous Media 120, 1, 37-66.

Whitson C.H., Fevang Ø. (1997) Generalized pseudopressure well treatment in reservoir simulation, in: Paper Presented at the Proc. IBC Conference on Optimisation of Gas Condensate Fields, 26-27 June, Aberdeen, United Kingdom.

Whitson C.H., Fevang Ø., Sævareid A. (1999) Gas condensate relative permeability for well calculations, in: Paper Presented at the SPE Annual Technical Conference and Exhibition, 3-6 October, Houston, Texas. 